\title{
Furanodienone induces G0/G1 arrest and causes apoptosis via the ROS/MAPKs-mediated caspase-dependent pathway in human colorectal cancer cells: a study in vitro and in vivo
}

\author{
Ying Jiang ${ }^{1}$, Xiaoqin $\mathrm{Wang}^{1}$ and Daode $\mathrm{Hu}^{*, 1}$
}

Furanodienone, a major bioactive constituents of sesquiterpene derived from Rhizoma Curcumae, has been proven to possess the potent anticancer efficacy on human breast cancer cells. Here, we investigated the cytotoxicity of furanodienone on human colorectal carcinoma cell lines in vitro and in vivo, as well as its underlying molecular mechanisms in the induction of apoptosis. In this study, we found that furanodienone significantly inhibited proliferation of RKO and HT-29 cells, induced mitochondrial dysfunction characterized by collapse of mitochondrial transmembrane potential and reduction of ATP level, and promoted the production of reactive oxygen species (ROS) that functions upstream of caspase-dependent apoptosis. The antioxidant $\mathrm{N}$-acetyl cysteine, a ROS scavenger, abolished this apoptosis induced by furanodienone. In addition, furanodienone elevated the expression of p-p38, p-JNK, but decreased p-ERK, as a result of the produced ROS. The specific inhibitors U0126, SP600125 and SB202190 attenuated the expression of MAPKs, and regulated the expression of cleaved caspase-8, -9 and -3 . Furthermore, the potential inhibitory effect of furanodienone on CRC cells was also corroborated in mouse xenograft model. In conclusion, the results demonstrated that furanodienone-triggered ROS plays a pivotal role in apoptosis as an upstream molecule-modulating activity of caspases in mitochondrial pathway via stimulating MAPKs signaling pathway. Our finding may provide a novel candidate for development of antitumor drugs targeting on colorectal cancer.

Cell Death and Disease (2017) 8, e2815; doi:10.1038/cddis.2017.220; published online 25 May 2017

Colorectal cancer (CRC) is one of the commonest malignancy and the third leading cause of cancer-related deaths worldwide. ${ }^{1}$ In the United States alone, the incidence of CRC increases faster with an approximation of 134490 new cases in 2016 in both sexes. ${ }^{2}$ At the same year in China, the new cases rose to 274841 , and the mortality was estimated 132110 cases, which takes up 48\% in colon-related death. ${ }^{3,4}$ Although advancements in diagnosis and development of adjuvant therapy such as radiofrequency ablation, radiation therapy and chemotherapy for CRC have provided useful palliation, ${ }^{5}$ the 5 -year relative survival rate from 2005 to 2011 was still $66 \%$ compared to that of $60 \%$ in the past decade. ${ }^{2}$ Furthermore, the survival rate tends to be $58.3 \%$ in the first 10 years after diagnosis. ${ }^{6}$ At present, the standard treatment modality for these patients is surgery in combination with chemotherapeutic regimens based on 5-Fluorouracil (5-FU) or leucovorin. However, the classic anticancer agents is frequently attenuated due to the development of resistance to chemotherapy. ${ }^{7}$ In addition, high-dose usage of these chemotherapeutic drugs did not improve the cure rate during the last decade and also brought considerable adverse side effects such as systemic toxicity. Therefore, there is an urgent need to screen novel drugs or metabolites that are capable of targeting on specific cancer.
Recently, there have been increasing attentions on exploration and application of natural plants owing to their merit of potent pharmacological activity. ${ }^{8-13}$ Furanodienone is one of the major bioactive constituents derived from traditional Chinese medicine Rhizoma Curcumae. ${ }^{14}$ In our recent study, it was demonstrated that furanodienone possessed higher cytotoxic activity against CRC cells in comparison to other widely studied essential oils such as curdione, curcumol and germacrone from $R$. Curcumae. ${ }^{15}$ Although it was reported furanodienone inhibited MCF-7 cell proliferation by interfering with HER2 signaling pathway, ${ }^{16,17}$ the possible molecular mechanisms of its inhibitory activity on human colon cancer cells have never been investigated.

It is well established that deregulation in the process of oxidative phosphorylation (OXPHOS) has a key role in cells fate. Reactive oxygen species (ROS) majorly originated from OXPHOS regulate cells growth and the redox status, affecting biochemical processes. Actually, ROS have a dual effect on maintaining the normal physiological activities within cells. Under normal conditions, a moderate level of ROS is wellcontrolled to modulate apoptosis, proliferation and inflammatory responses, contributing to a beneficial environment for cells survival. ${ }^{18,19}$ However, ROS in a specific condition, especially when the level of free radicals far exceeds its scavenging ability in cells, can damage cellular components

\footnotetext{
1Department of Clinical Pharmacology, Shanghai General Hospital, Shanghai Jiaotong University School of Medicine, Shanghai 200080, China

${ }^{*}$ Corresponding author: D Hu, Department of Clinical Pharmacology, Shanghai General Hospital, Shanghai Jiaotong University School of Medicine, 100 Haining Road, Shanghai, Hongkou 200080, China. Tel: +86 0216324 0090; Fax: +86 0216324 0417; E-mail: shanghaiyao@ @ina.com

Received 18.1.17; revised 09.4.17; accepted 10.4.17; Edited by A Stephanou
} 
such as DNA, protein and lipids, thus interfering with cellular signaling pathways. Excessive accumulation of ROS has been reported to amplify death execution through redox-sensitive signaling by disrupting the expression of several apoptotic effectors such as Bcl-2, caspases and cytochrome $c$ in the mitochondrial-mediated apoptotic a
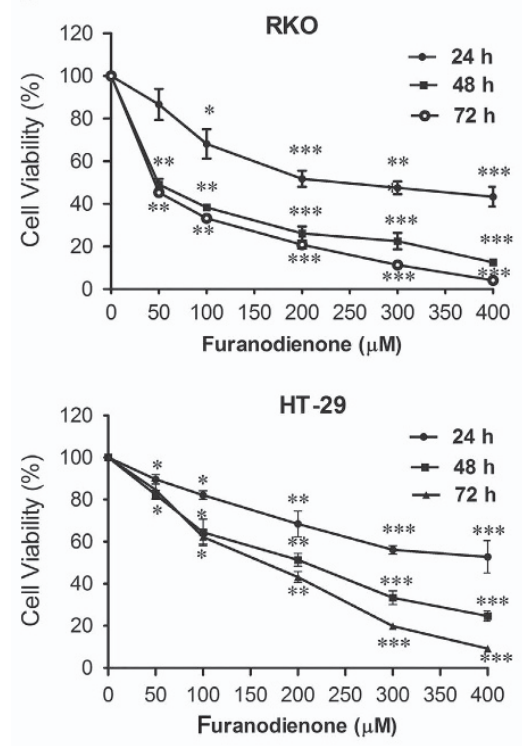

C
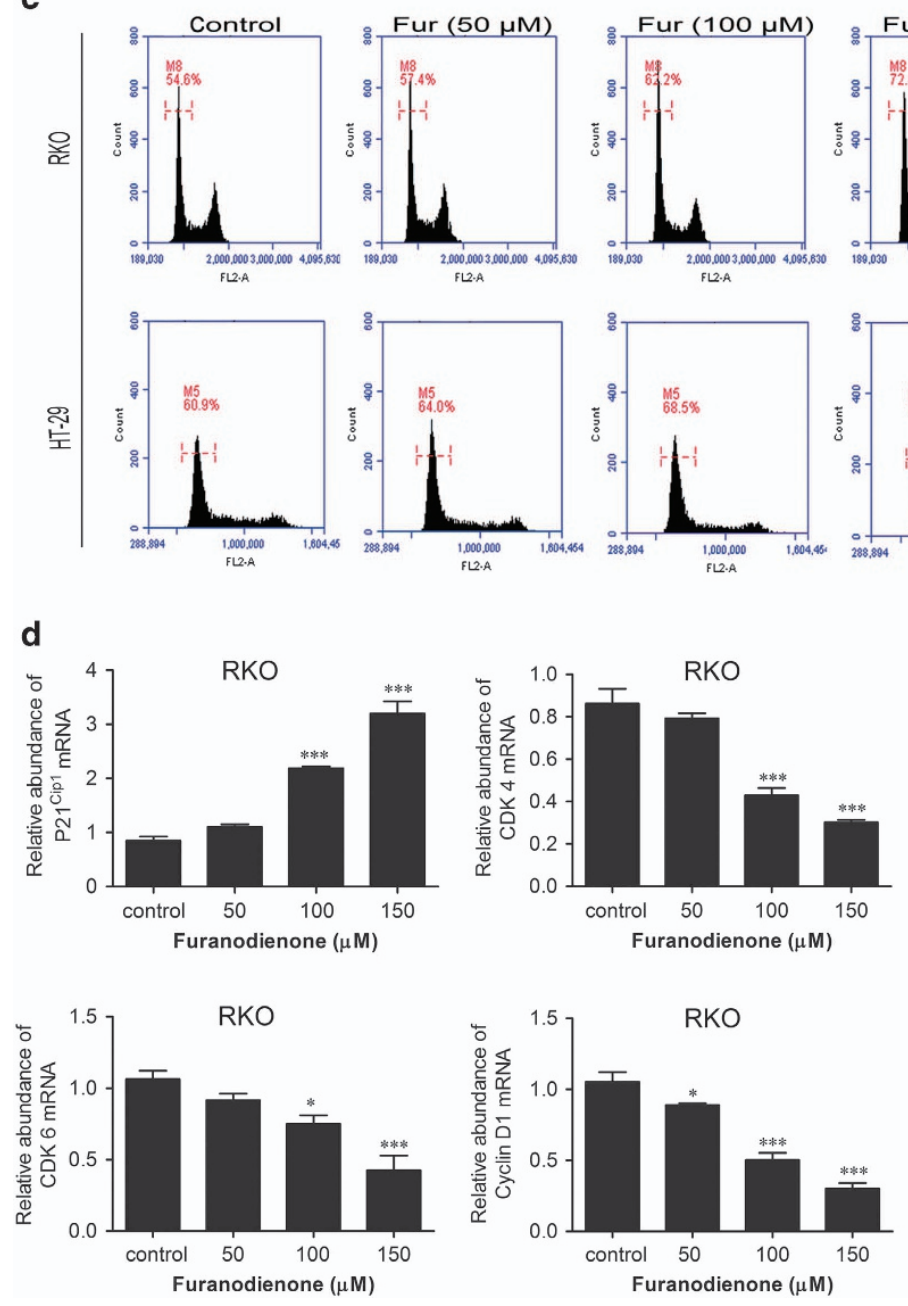

b

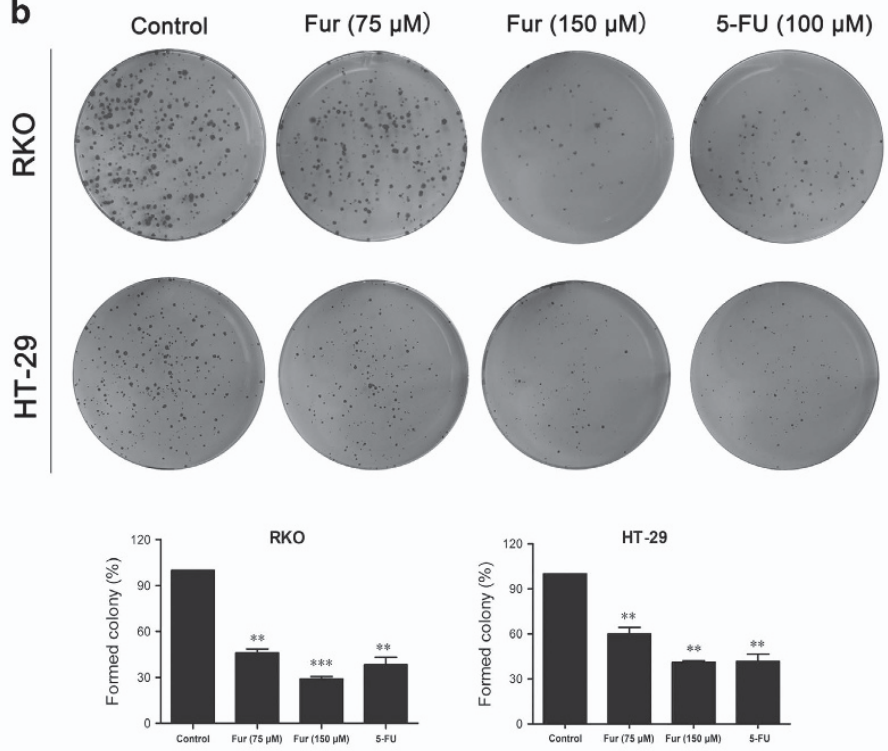

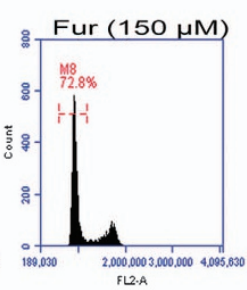

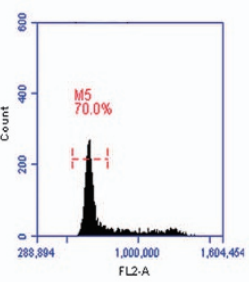

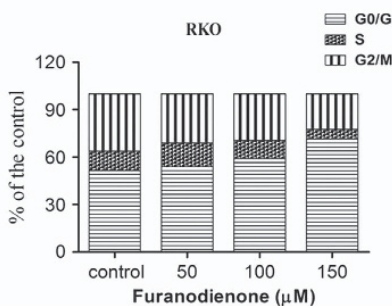

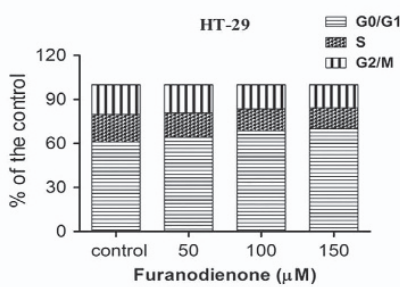

e

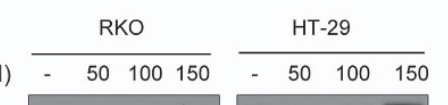

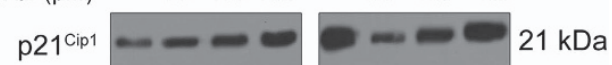

CDK $4-\ldots \ldots-m$ kDa

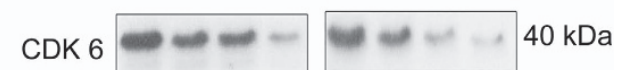

Cyclin D1 $\longrightarrow-\infty-\infty \mathrm{kDa}$

Cyclin E $-\infty-\cdots \infty \mathrm{kDa}$

CDK $2--\infty-\infty$ kDa

GAPDH 
pathway, ${ }^{20}$ which provides a train of thoughts to develop redox-modifying drugs.

ROS generation involved increasingly in cell proliferation and apoptosis via regulation of MAPK family members comprising of ERK, JNK and p38 MAPK in the action of some chemotherapeutic drugs. ${ }^{21,22}$ MAPKs play an essential role in diverse cellular programs including modulation the pro and anti-apoptotic proteins located in mitochondria. ${ }^{23}$ For example, in response to oxidative stress, the activation of JNK promotes the apoptotic processes, in a manner of inhibition of $\mathrm{Bcl}-2$ function. ${ }^{24}$ Furthermore, degradation of $\mathrm{Bcl}-2$ was found to associate with downregulation of ERK when exposed to oxidative stress. ${ }^{25}$ Accordingly, targeting activation of the ROS/MAPK signaling pathway may be a promising strategy for enhancement of antitumor efficacy in the treatment of human cancers.

The aim of the present study was to characterize the cytotoxic effects and molecular mechanisms of furanodienone on RKO or HT-29 colon cancer cells in vivo and in vitro. Collectively, it was showed for the first time the evidence that furanodienone induces G0/G1 phase arrest and causes apoptosis depending on the production of ROS that activates MAPKs signaling pathway in a caspase-dependent manner in RKO and HT-29 cells.

\section{Results}

Furanodienone inhibits colony formation and induces cell cycle G0/G1 arrest. Five types of CRC cells were used to evaluate the death-inducing activity of furanodienone, including RKO (poorly differentiated cell), sw480 (poorly differentiated cell), HT-29 (intermediate-differentiated cell), sw620 (intermediate-differentiated cell) and LoVo (welldifferentiated cell). As shown in Supplementary Figure S1a, the $\mathrm{IC}_{50}$ in $24 \mathrm{~h}$ were, respectively, $156.4 \mu \mathrm{M}$ (RKO), $73.7 \mu \mathrm{M}$ (sw480), 251.1 $\mu \mathrm{M}$ (HT-29), 412.5 $\mu \mathrm{M}$ (sw620) and $573.8 \mu \mathrm{M}$ (LoVo), while that in $48 \mathrm{~h}$ were $51.8 \mu \mathrm{M}$ (RKO), 44.18 $\mu \mathrm{M}$ (sw480), 168.9 $\mu \mathrm{M}$ (HT-29), 314.2 $\mu \mathrm{M}$ (sw620) and $502.1 \mu \mathrm{M}$ (LoVo), respectively. Furanodienone inhibits proliferation on all of these $\mathrm{CRC}$ cells, indicating the inhibitory effects of furanodienone are cell line-independent. RKO and HT-29 as respective representative of poorly differentiated and intermediate-differentiated CRC cells were taken as our studied objects. As shown in Figure 1a, RKO and HT-29 cells viability were both inhibited in a time- and dose-dependent manner. The $\mathrm{IC}_{50}$ for 5-FU (Supplementary Figure S1b) in $24 \mathrm{~h}$ was calculated as $67.4 \mu \mathrm{M}$ (RKO) or $85.2 \mu \mathrm{M}$ (HT-29), showing a bit stronger in cytotoxicity compared to furanodienone. Additional colony formation assay was conducted to confirm the antiproliferative effect of furanodienone on these two colon cancer cells (Figure 1b). The formed colonies in both cells were significantly reduced with the raising concentrations of furanodienone. While compared with 5-FU, furanodienone at $150 \mu \mathrm{M}$ showed similar cytotoxic effects on RKO and HT-29 cells, indicating that furanodienone can be regarded as a potential drug targeting $\mathrm{CRC}$.

To dissect whether the cells inhibition induced by furanodienone involves in cell cycle arrest, cell cycle distribution of both cells was evaluated using flow cytometry, and the expression of cell cycle regulatory proteins was analyzed by RT-qPCR and western blotting subsequently. The results in Figure 1c showed that furanodienone significantly increased cell number at G0/G1 phase and led to a corresponding decrease in G2/M phase compared to the control, however, there was no obvious effect on $S$ phase in both cells. RT-qPCR results showed that mRNA expression of the key related checkpoint factors in G0/G1 phase including $\mathrm{p} 21^{\mathrm{Cip} 1}$ was significantly upregulated in $\mathrm{RKO}$ cells in a dose-dependent manner, whereas mRNA expression of cyclin D1, CDK 4 and CDK 6 was decreased (Figure 1d), in accordance with the results from western blotting (Figure 1e). Besides, CDK 2 and cyclin E protein levels in both cells were downregulated (Figure 1e). All these data manifested that G0/G1 phase arrest may be accounted to the furanodienone-induced antiproliferation against RKO and HT-29 cells.

Furanodienone induces apoptosis of colorectal cells. Apoptosis can be regarded as one of the critical molecular mechanisms in drug-induced cell death. To figure out if apoptosis is responsible for the cells inhibition triggered by furanodienone, we performed DAPI staining. Cells stained with DAPI presented brighter blue fluorescence in high-dose group compared with the control group in both cells (Figure 2a). As in the flow cytometric analysis, there were significant increases with an elevation of furanodienone in a dose-dependent manner in both early and late apoptosis, while the addition of 75 and $150 \mu \mathrm{M}$ furanodienone increased the apoptotic rates to $19.45 \pm 2.37 \%$ and $27.34 \pm 0.79 \%$, respectively, compared with $2.34 \pm 0.45 \%$ in control group in RKO cells, whereas $12.4 \pm 1.08$ and $20.64 \pm 3.02 \%$ apoptosis at the concentration of 75 and $150 \mu \mathrm{M}$ furanodienone were observed in HT-29 cells compared with $2.89 \pm 0.26 \%$. 5 -FU in $100 \mu \mathrm{M}$ showed a similar proapoptotic effect on both cells compared with that in $150 \mu \mathrm{M}$ furanodienone. AO/EB staining assay confirmed the apoptotic characterizations in furanodienone-treated RKO cells (Figure 2c), consistent with a raising level in $\mathrm{LDH}$ release with an increase in furanodienone concentration for $24 \mathrm{~h}$ (Figure $2 \mathrm{~d}$ ). Thus, the overall study above suggested that furanodienone induced apoptosis in RKO and HT-29 cells.

Figure 1 Furanodienone inhibits cells proliferation and induces G0/G1 arrest in human colorectal cancer cells. (a) The antitumor effect of furanodienone on RKO and $\mathrm{HT}-29$ cells was measured by CCK-8 assay. Cells were treated with raising doses of furanodienone for 24,48 and $72 \mathrm{~h}$. Each experiment performed in triplicate. (b) Colony formation assay of RKO and HT-29 cells with control, furanodienone or 5-FU. (c) Furanodienone induced G0/G1 phase arrest. RKO and HT-29 cells were exposed to furanodienone $(0,50,100$ and $150 \mu \mathrm{M})$ for $24 \mathrm{~h}$ followed by flow cytometric assay. The percentage of cell cycle distribution was showed as mean \pm S.D. from three independent experiments. The mRNA expression of p2 ${ }^{\mathrm{Cip} 1}, \mathrm{CDK} 4, \mathrm{CDK} 6$ and cyclin D1 in RKO cells treated with furanodienone for $24 \mathrm{~h}$ were detected using RT-qPCR (d). The expression of G0/G1 phase-related proteins were analyzed by western blotting (e). ${ }^{*} P<0.05,{ }^{* \star} P<0.01,{ }^{* * *} P<0.0001$, significantly different compared with control 

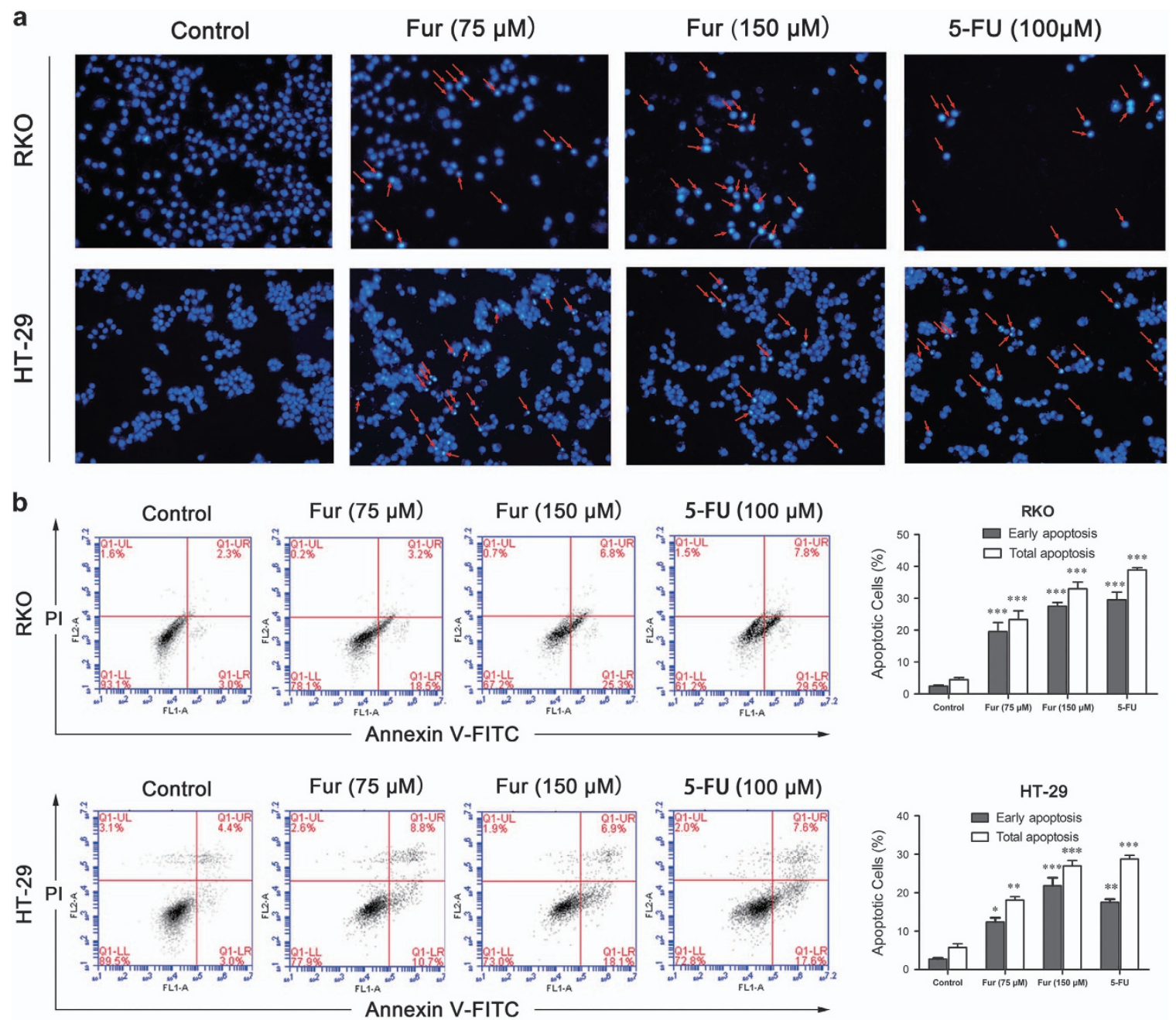

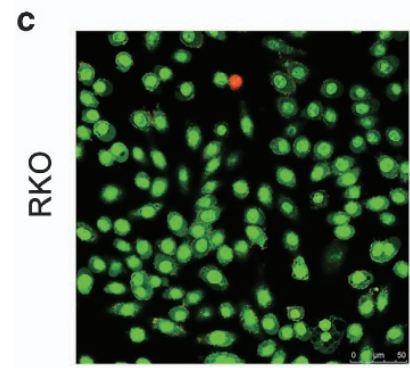

Control

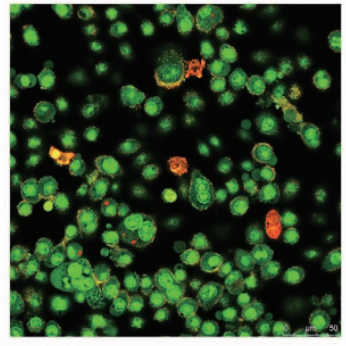

Fur $(75 \mu \mathrm{M})$

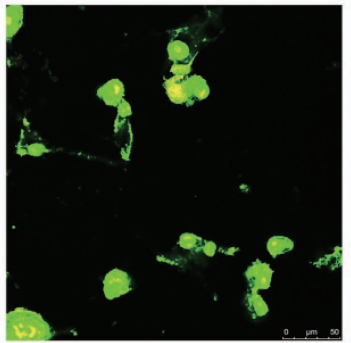

Fur $(150 \mu \mathrm{M})$
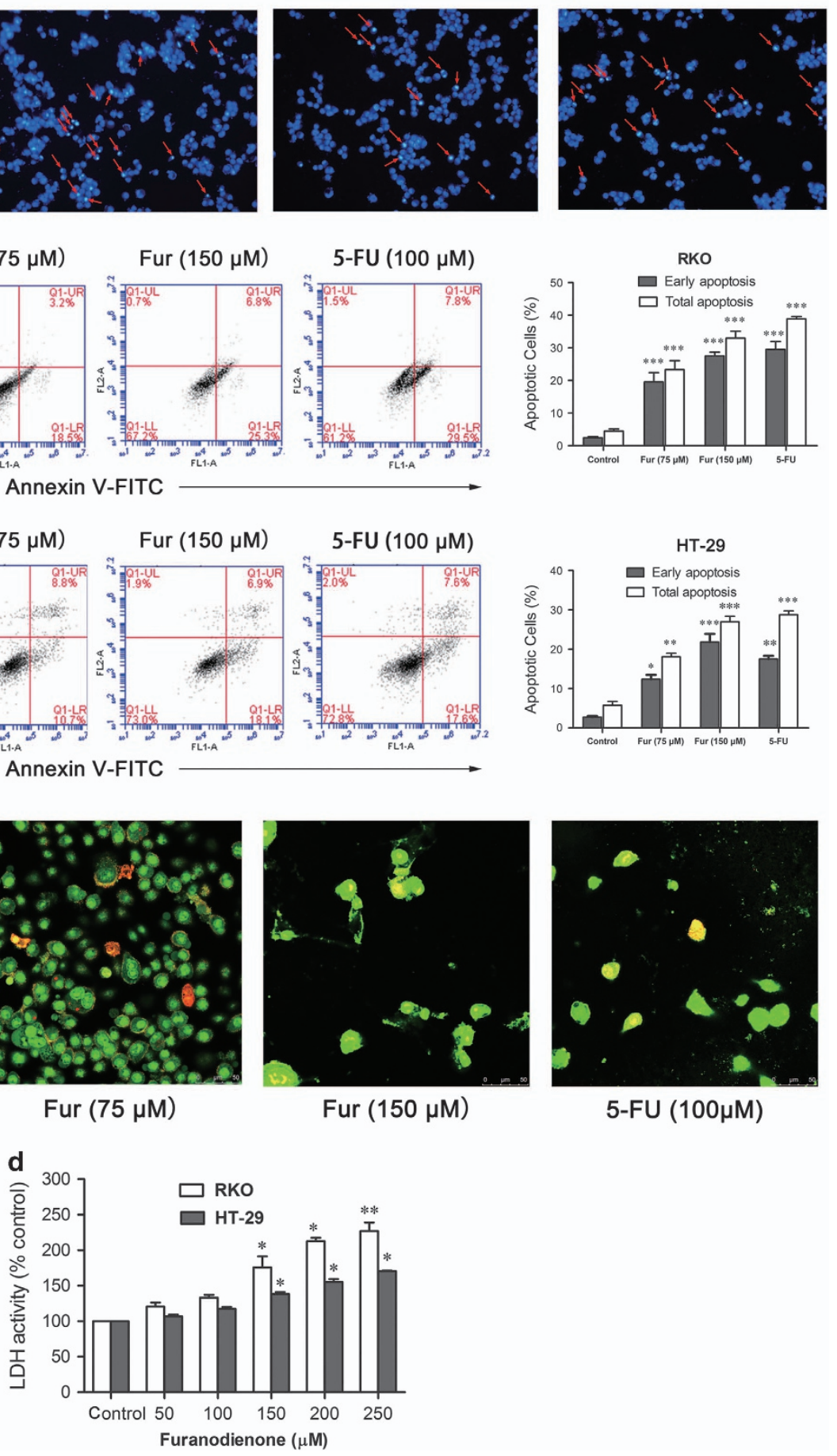
Furanodienone induces cells apoptosis through caspase-dependent extrinsic and intrinsic pathways. Apoptosis can be induced either by extrinsic pathway through the activation of cell surface death receptors or by intrinsic pathway through the release of mitochondria-related signal factors, ${ }^{26,27}$ while activation of caspase- 8 and caspase- 9 is required, respectively. To determine which pathway associated with the furanodienone-induced apoptosis, we detected the activity of caspase-8, -3 and -9 . As shown in Figure $3 a$, an obvious increase in caspase- 9 and -3 activity has been observed in both cells, whereas a relative minor effect on that of caspase-8. Pretreatment with a specific caspase-9 inhibitor (z-LEHD-fmk) partially reversed the apoptosis in RKO cells (Figure 3b), while the general caspases inhibitor (z-VAD-fmk) exhibited a similar effect with that of z-LEHD-fmk, thus we suspected furanodienoneinduced apoptosis involves mainly in the intrinsic pathway. To confirm the involvement of mitochondrial pathway in induction of apoptosis, changes of the mitochondrial membrane potential $\left(\Delta \psi_{m}\right)$ were tested with fluorescent mitochondrial probe JC-1. Flow cytometric analysis in Figure $3 \mathrm{C}$ showed there was a significant loss in $\Delta \psi_{m}$, which was evidenced by accumulations of cells stained with green fluorescence after exposure to furanodienone. The relative ATP level investigation showed a statistically significant drop in intracellular ATP levels compared to the control (Figure 3d). Moreover, following treatment with furanodienone, the expression of Bax, cytochrome $c$, Smac/DIABLO and AIF proteins were obviously increased and, in contrast, Bcl-2, Bcl$\mathrm{Xl}$ and survivin were decreased in a time-dependent manner (Figure 3e), implying activation of the intrinsic apoptosis pathway in furanodienone-induced cell death. Taken together, the apoptosis induced by furanodienone was dependent on caspase-dependent intrinsic and extrinsic signaling pathways, mainly by the intrinsic apoptotic pathway.

Intracellular ROS generation involves in mitochondriamediated cell death in furanodienone-treated cells. ROS is verified a pivotal role in the activation of cell death pathways. We next explored if the apoptotic effect of furanodienone was a function of ROS modulation within cells. The change of ROS levels in both cells after exposure to furanodienone was measured by DAFH-DA probe. As illustrated in Figure $4 a$, furanodienone markedly increased ROS production, while $\mathrm{N}$-acetyl cysteine (NAC) attenuated it. MDA as one of the symbolic markers of oxidative stress was observed to be enhanced by twofold in furanodienone group, whereas the activity of SOD and CAT was downregulated, together with the content of GSH (Figure 4b). However, treatment with NAC remarkably reversed the elevated MDA level, while the activity of SOD and CAT, and GSH level were upregulated. CCK-8 analysis in Figure 4c further suggested that NAC abolished furanodienone-induced apoptosis, and the expression of cleaved caspase- $3,-9$ and cleaved PARP in mitochondrial pathway was reduced in the presence of NAC (Figure 4d). Thus, there is a reason to believe that ROS involves in the furanodienone-induced apoptosis via activating the mitochondrial apoptotic pathway. To elucidate how ROS functions in mitochondrial pathway, cells preincubated with the general caspases inhibitor z-VAD-fmk were analyzed by flow cytometry. ROS production was explosively increased at $150 \mu \mathrm{M}$ furanodienone within $24 \mathrm{~h}$, but a significant reduction was observed on a pretreatment of NAC, whereas it remained unchanged in inhibitor group compared with that in the furanodienone group (Figure 4e), which indicated that ROS is a upstream molecule-modulating caspase-dependent reaction. The results above suggested that the antitumor activity of furanodienone was a function of mitochondriaapoptotic execution secondary to the modulation of ROS.

Furanodienone induces apoptosis via activating MAPKsmediated mitochondrial pathway dependent of ROS production. The possible interlink between oxidative stress and MAPKs pathway in RKO and HT-29 cells were examined by western blotting. Furanodienone significantly induced the phosphorylations of p38 and JNK in a dose-dependent manner, and unexpectedly, the expression of $p$-ERK was reduced (Figure 5a). The antioxidant NAC reduced p-p38, p-JNK and increased p-ERK levels in Figure 5b. However, expression of p38, JNK and ERK remained unchanged. We further illuminated the relationship between MAPKs and furanodienone-induced caspase-dependent apoptosis. RKO cells were pretreated with three specific inhibitors, respectively, U0126 (an ERK inhibitor), SP600125 (a JNK inhibitor) and SB202190 (a p38 inhibitor) for $2 \mathrm{~h}$, and then analyzed by western blotting. As shown in Figure 5c, SP600125 and SB202190 significantly inhibited the expression of cleaved caspase-8, -9 and -3, while U0126 exhibited an opposite trend. These results suggested that furanodienone-induced ROS activated MAPKs signaling pathway, which further elaborated the mitochondria-mediated apoptosis via modulating the caspase-dependent pathway.

Furanodienone inhibits tumor growth in a xenograft murine model. We established the BALB/c-nu models by transplanting RKO cells subcutaneously into the right flank of mice to confirm the potential inhibitory effect of furanodienone on CRC cells in vivo. When the tumor size reached $50 \mathrm{~mm}^{3}$, the mice were divided into two groups: control (10\% DMSO) and furanodienone $(2 \mathrm{mg} / \mathrm{kg})$, followed by intraperitoneally injection every other day for seven times. The average size of the tumors in $2 \mathrm{mg} / \mathrm{kg}$ furanodienone-treated group was

\footnotetext{
Figure 2 Furanodienone induces apoptosis in CRC cells. (a) Apoptotic nuclear morphology changes induced by furanodienone or 5-FU were assessed by DAPI staining and visualized by fluorescence microscopy at a magnification of $\times 200$. Red arrows indicate chromatin and nuclear fragmentation. (b) Cells were treated with raising concentrations of furanodienone or $100 \mu \mathrm{M} \mathrm{5-FU} \mathrm{for} 24 \mathrm{~h}$. The apoptotic rates were measured and analyzed by flow cytometry using Annexin V-FITC/PI staining. Each experiment performed in triplicate. (c) Apoptotic cells treatment with furanodienone $(75$ and $150 \mu \mathrm{M})$ or $5-\mathrm{FU}(100 \mu \mathrm{M})$ for $24 \mathrm{~h}$ were imaged using AO/EB staining at a magnification of $\times 400$. Cells exhibiting yellow or red fluorescence indicated apoptosis or necrosis. (d) Dose-dependent induction of LDH leakage to cells after furanodienone exposure for $24 \mathrm{~h}$. ${ }^{*} P<0.05$, ${ }^{* \star} P<0.01,{ }^{* * *} P<0.0001$, significantly different compared with control. Each experiment performed in triplicate
} 

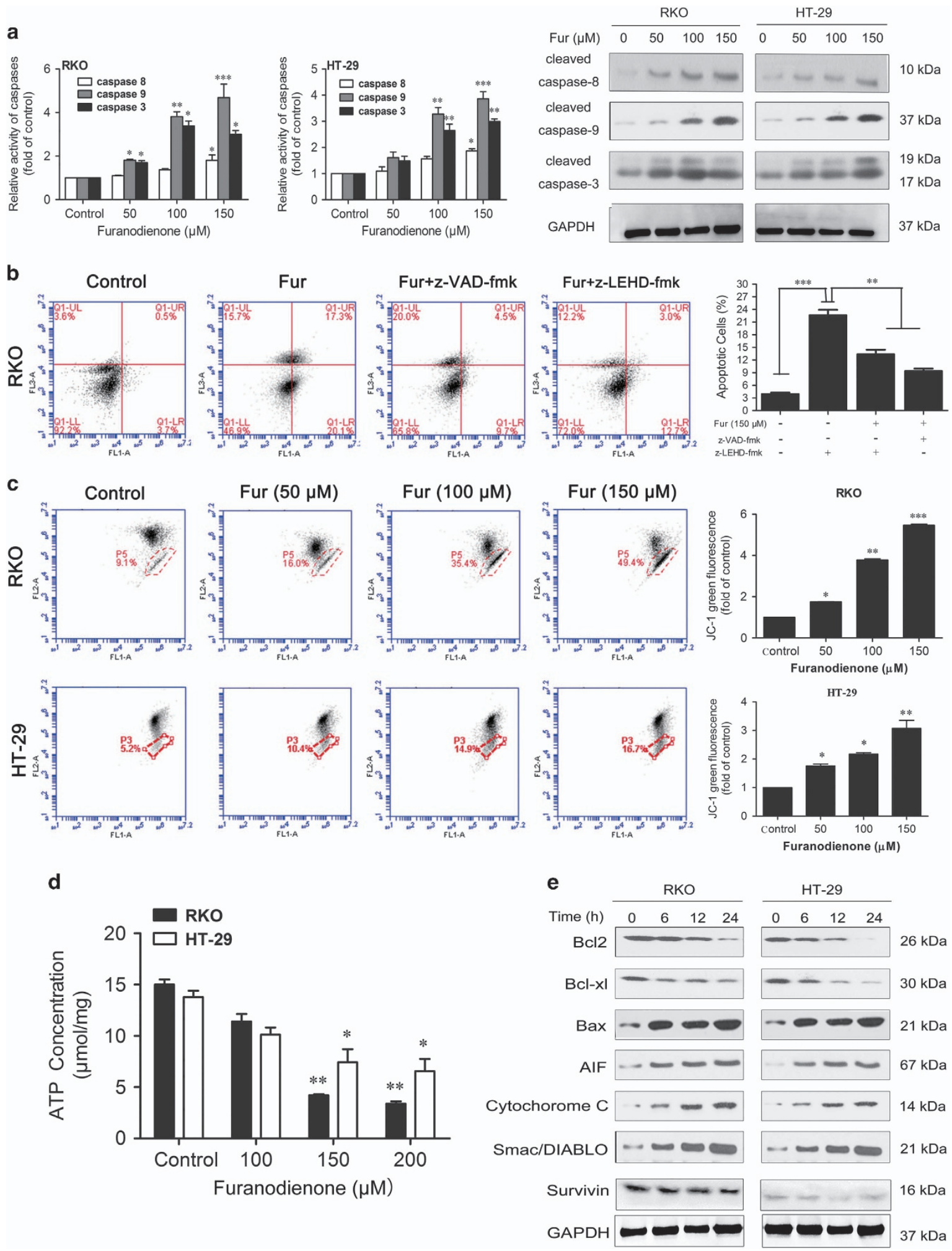

Figure 3 Furanodienone-induced apoptosis involves mitochondrial pathway in CRC cells. (a) Activity of caspase-8, -3 and -9 in both cells after exposure to furanodienone were detected using activity assay, and the expression of cleaved caspase-8, -3 and -9 proteins were measured using western blot. (b) Pretreatment with the general caspases inhibitor z-VAD-fmk or the specific caspase-9 inhibitor z-LEHD-fmk reserved apoptosis in RKO cells after exposure of $150 \mu \mathrm{M}$ furanodienone. Cells were pretreated with $100 \mu \mathrm{M}$ z-VAD-fmk or $100 \mu \mathrm{M}$ z-LEHD-fmk for $2 \mathrm{~h}$ before exposed to furanodienone. The apoptotic rates were detected using flow cytometry. (c) The mitochondrial membrane potential were investigated using JC-1 staining. Results indicating intensity of green fluorescence showed as folds of control from three independent experiments. (d) Twenty-four hours after furanodienone treatment, ATP concentration was measured. The results were presented as the mean \pm S.D. of triplicate experiments. (e) Proteins in mitochondrial pathway were analyzed using western blotting. ${ }^{*} P<0.05,{ }^{* \star} P<0.01,{ }^{* *} P<0.0001$, significantly different compared with control 
reduced to $374.4 \mathrm{~mm}^{3}$ compared to $648.2 \mathrm{~mm}^{3}$ in $10 \%$ DMSO-treated group. Furanodienone significantly inhibited the growth of tumor size, but exerted a minor effect on its body weight (Figures $6 a$ and $b$ ). As results presented in Figure $6 c$, furanodienone increased level of cleaved caspase3 , p-P38 and p-JNK, but reduced that of the p-ERK. TUNELpositive cells were significantly increased in experiment group, and HE staining assay suggested that furanodienone has no overall toxicity on tissues (Figure 6d). Immunohistochemistry showed positive stains in cleaved caspase-3, p-P38 and p-JNK, while a negative in p-ERK, which was quantified by IPP software in terms of mean optical density (Figure 6d). All these results revealed that furanodienone inhibits growth of CRC cells in vivo with low toxicity.

\section{Discussion}

R. Curcumae, a member of the genus Curcuma, is cultivated in tropical and subtropical countries, especially in China, and the extracted sesquiterpene volatile oils possess powerful anticancer properties. ${ }^{28,29}$ Furanodienone, a main bioactive constituent in sespuiterpenes from $R$. Curcumae, has been reported the potential antitumor potent against human breast cancer cells. ${ }^{17}$ Our previous study found that furanodienone exerts the best inhibitory effect on the proliferation of CRC cells among other three essential oils, implying that furanodienone may have a positive value in treatment of CRC. ${ }^{30}$ However, the cytotoxic effects and its underlying molecular mechanisms have not been elaborated. In this study, the potential cytotoxic effects of furanodienone on CRC were comprehensively investigated using both in vitro and in vivo models. Our results for the first time presented that furanodienone induced G0/G1 cell cycle arrest and caused apoptosis.

Anticancer effect is usually mediated by the inhibition of proliferation and cell cycle arrest. Cell cycle deregulation is one of the hallmarks in tumor cells and mutations in key checkpoint genes, especially the family of cyclin-dependent kinase (CDK), contributing to tumor-associated cell cycle defects. ${ }^{31}$ The progression of cell cycle is driven by different cyclin-CDK complexes via phosphorylating the target proteins. CDK 4 and CDK 6 are essential in the progression of G1 phase by forming the CDK 4/6-cyclin D1 complexes, while cyclin $E$ and CDK 2 were necessary in the late of G0/G1 cell phase. ${ }^{32,33} \mathrm{CDK}$ inhibitor, p21 ${ }^{\mathrm{Cip} 1}$, has been reported to be related with the G0/G1 phase arrest by inactivation of CDKcyclin complex (CDK 4/cyclin D and CDK 2/cyclin E). ${ }^{32}$ Consistent with results from the previous study, ${ }^{16}$ our study reflected that furanodienone increased the proportion of G0/ G1 phase, and reduced the cell population in $\mathrm{G} 2 / \mathrm{M}$ phase in RKO and HT-29 cells, according to the flow cytometric analysis. Further RT-qPCR revealed that cyclin D1, CDK 4 and CDK 6 mRNA expressions were reduced, whereas p21 2 ip1 mRNA was increased in RKO cells. In addition, furanodienone led to a decrease in accumulation and activation of G0/G1 phase-related cycle regulator. Thus, the reduction in level of CDK 4, CDK 6, cyclin D1, CDK 2 and cyclin $\mathrm{E}$ proteins and upregulation in $\mathrm{p} 21^{\mathrm{Cip} 1}$ may be explained for G0/G1 phase arrest induced by furanodienone.
Apoptosis (or type-I programmed cell death), firstly put forward by Keer in $1972,{ }^{34}$ was recognized as a physiological process that is characterized by a wide range of pathological conditions or morphological changes such as cell shrinkage, chromatin condensation, cellular fragmentation and plasma membrane blebbing. ${ }^{35,36}$ It was widely accepted that apoptosis can be stimulated through two major apoptotic pathways: the extrinsic cell surface death receptor-directed apoptotic pathway and the intracellular sensor-mediated apoptotic pathway, and both of which involve in the activation of caspases that are usually expressed in an inactive proenzyme form before being stimulated. Once activated, the caspases initiate the downstream pro-caspases followed by the activation of protease cascade. ${ }^{37}$ Caspase- 8 as an apical caspase and caspase- 9 as an important intracellular amplifier of caspase signaling downstream of mitochondria are, respectively, indispensable in the extrinsic and intrinsic apoptosis pathway. Present study found that furanodienone-treated cells activated caspase-3, -8 and -9 . Besides, the cleaved caspase3 level in tumor tissues treated with furanodienone was confirmed by immunohistochemical analysis (Figure 6d). The proapoptotic members (Bax, Bad and Bak) of Bcl-2 family that regulates the mitochondrial outer membrane permeabilization initiate the release of cytochrome $c$, Smac/DIABLO and AIF into the cytosol, however, $\mathrm{Bcl}-2$ and $\mathrm{Bcl}-\mathrm{xl}$ as anti-apoptotic members antagonize them by heterodimerising with proapoptotic proteins. ${ }^{38}$ In addition, ATP depletion and MMP collapse as signs of mitochondrial dysfunction, all account for the ultimately mitochondrial damages. ${ }^{39}$ In the present study, decrease in the $\mathrm{Bcl}-2 / \mathrm{Bax}$ ratio has been detected by western blotting, companying with the increasing accumulations of cytochrome $c$, Smac/DIABLO and AIF in the cytosol. Meanwhile, declines of MMP and ATP induced by furanodienone were recorded as well. Thus, we can draw the conclusion that mitochondria-mediated apoptotic pathway was involved in the furanodienone-induced cell apoptosis.

ROS as an important molecule takes part in regulations of cell death and survival in cancer cells. We confirmed furanodienone triggered excessive ROS production. As a result, the produced ROS elevated the level of MDA, which is one of the final products of lipid oxidation by oxidative stress. Meanwhile, activity of antioxidant enzymes (SOD and CAT) was inhibited by ROS, and the GSH content were reduced, which is consistent with some of the previous reports indicating an imbalance in oxidant/antioxidant system induced by oxidative stress. ${ }^{40,41}$ This may be explained by the inhibition of nuclear factor-erythroid-2-related factor 2 (Nrf2) signaling. Nrf2, a redox-sensitive basic-leucine zipper transcription factor, is essential for the cellular defense responses via transactivating genes of a large battery of antioxidant enzymes and phase II detoxifying enzymes to alleviate the burden of oxidative stress. ${ }^{42,43}$ The SOD and CAT are downstream genes induced by Nrf2 translocation and their activities were enhanced as adaptive intracellular responses to protect against oxidative damages. ${ }^{44,45}$ However, when the produced ROS cannot be eliminated in time, Nrf2 expression is counteracted by the activation of p53 in response to substantial generation of oxidative stress, which might account for the attenuated SOD and CAT activity. ${ }^{46}$ NAC as a source of $\mathrm{GSH}$ has a potent ability to promote the 


\section{8}

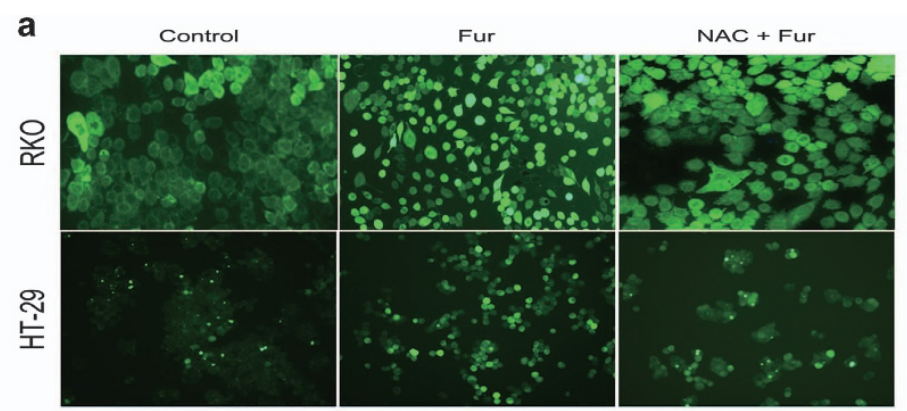

b
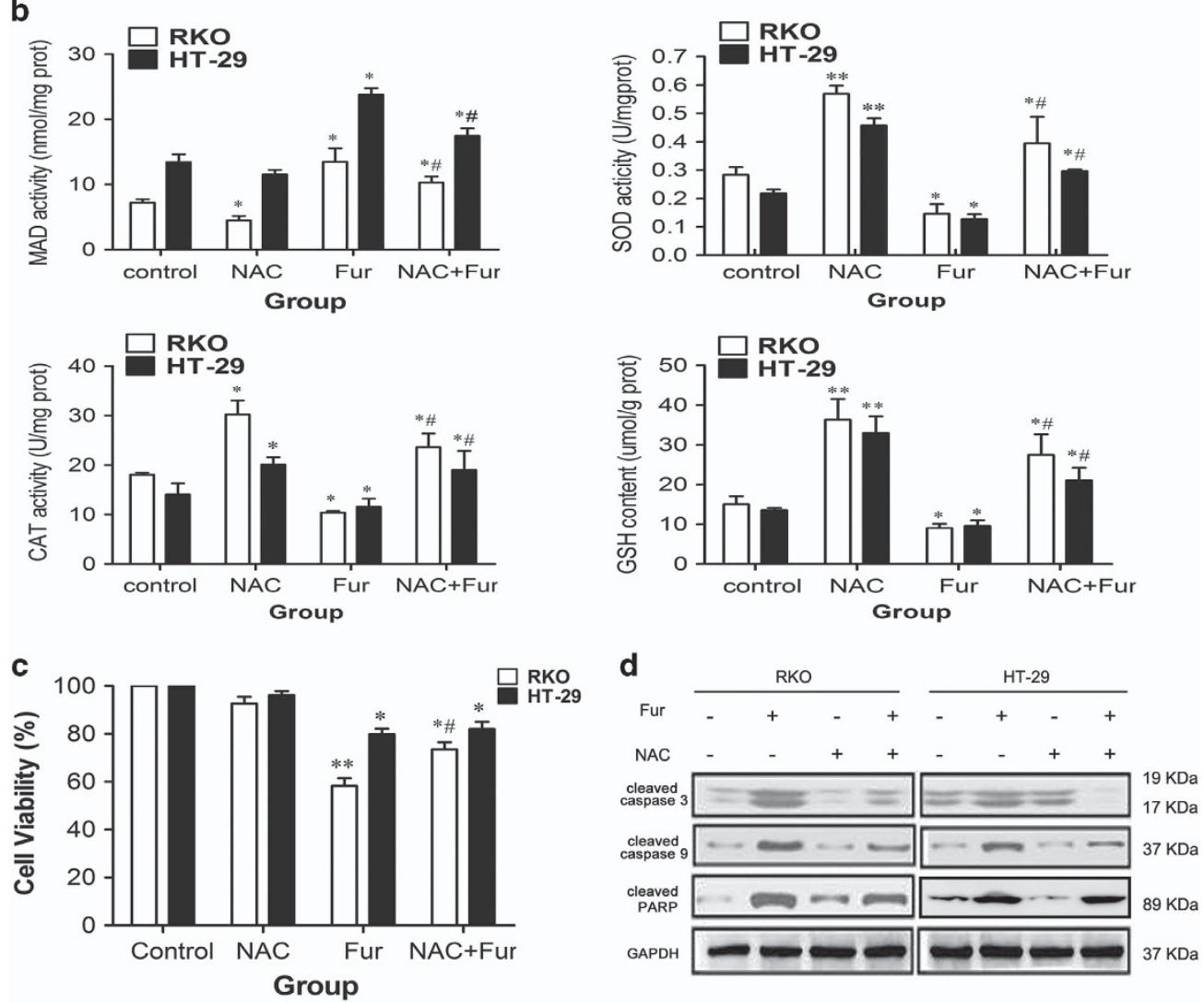

e
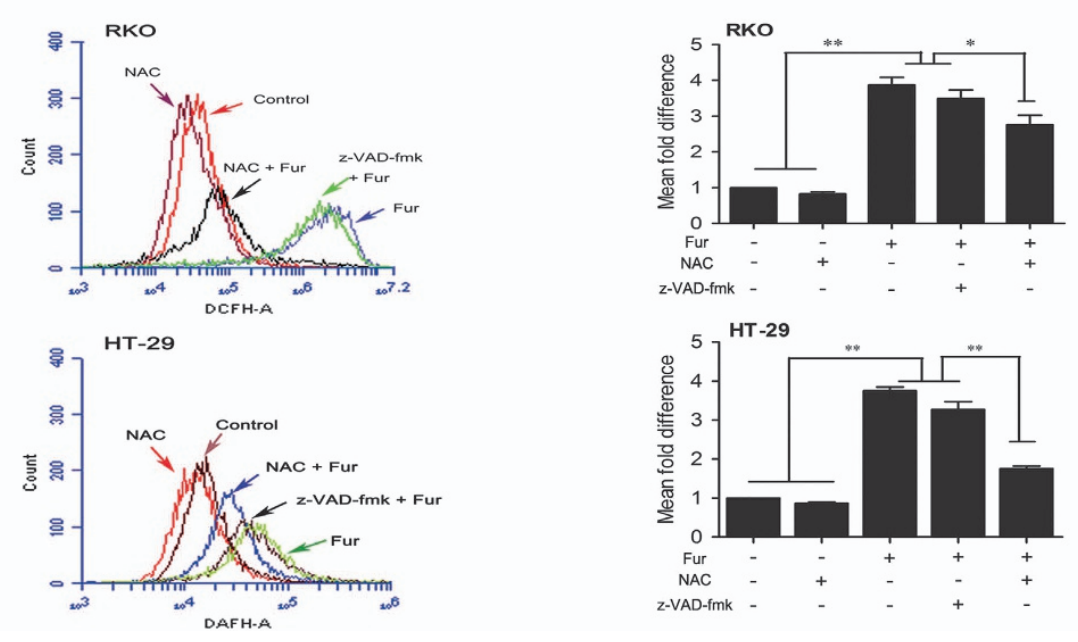
antioxidative system and the activation of the Nrf2 signaling. Pretreatment with NAC, the changes in MDA level, SOD or CAT activity, and GSH content were reversed. Furthermore, the activated Nrf2 facilitates the production of GSH. In the present study, the furanodienone-induced apoptosis potential was clearly a result of oxidative imbalance as indicated by enhanced level of ROS since NAC pretreatment abolished apoptosis induced by furanodienone (Figure 4c). Moreover, pretreatment with NAC significantly decreased caspase-3 and -9 expressions; in contrast, the level of cleaved PARP was upregulated. Furthermore, in accordance with a study conducted by Maillet et al., ${ }^{47}$ ROS as a upstream molecule regulates caspases' activation, indicating $\mathrm{ROS}$ involved in the mitochondrial pathway.
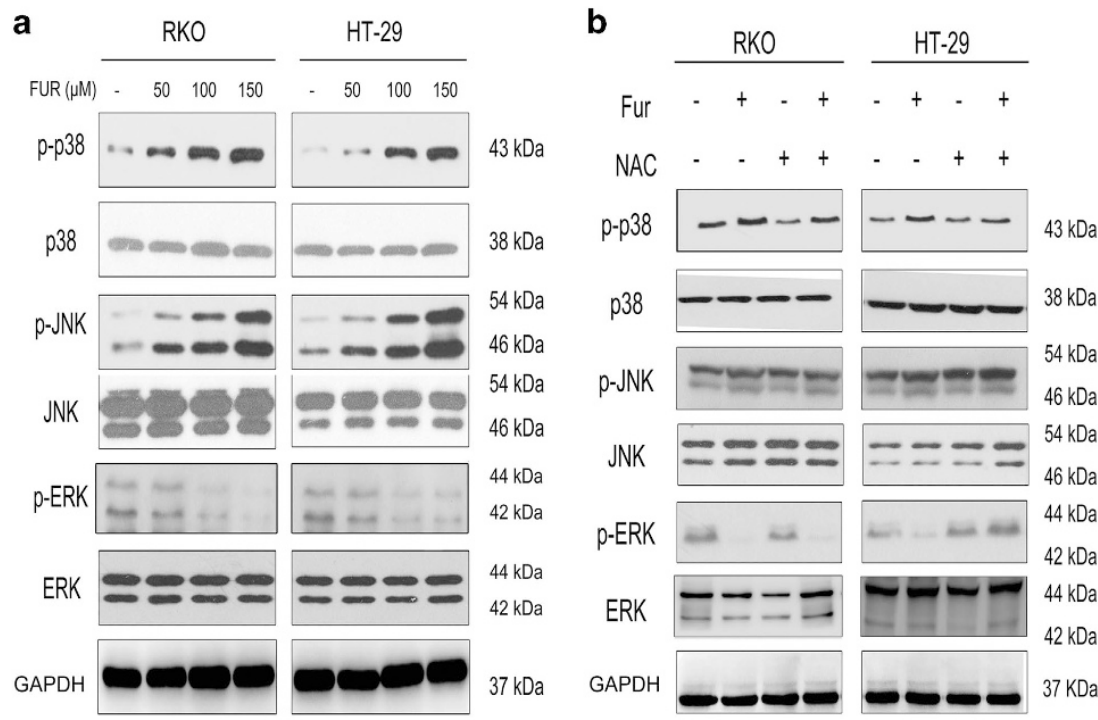

C

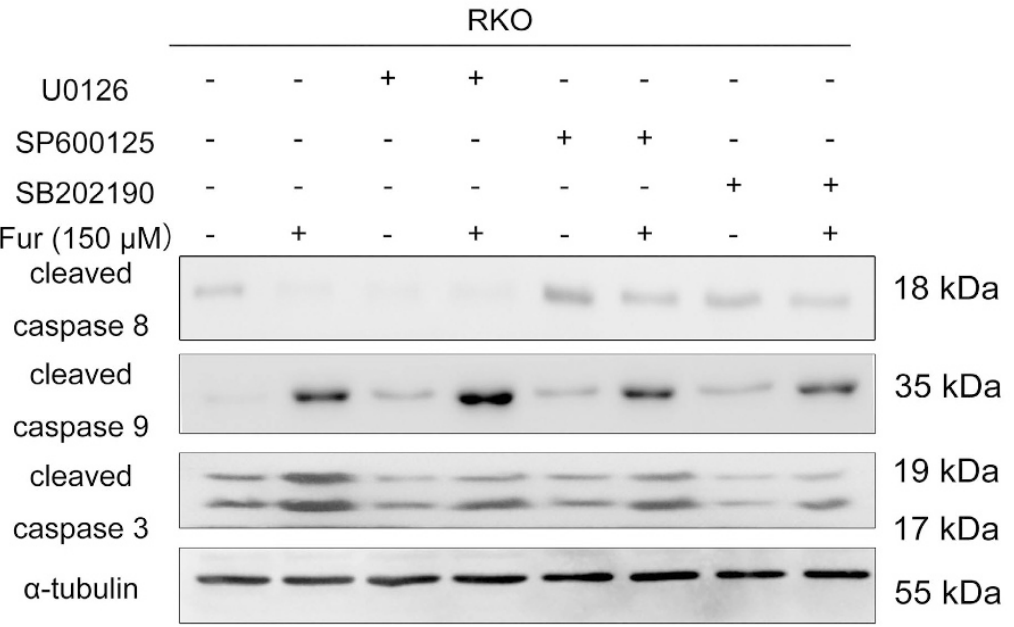

Figure 5 The produced ROS contributes to the MAPKs-mediated mitochondrial pathway in apoptosis induced by furanodienone. (a) The protein expressions of p-p38, p38, p-JNK, p-JNK, p-ERK and ERK were measured by western blotting. Cells exposed to varying concentrations of furanodienone $(50,100$ and $150 \mu \mathrm{M})$ were detected for the expression of MAPKs proteins. (b) Regulation of ROS/MAPKs-dependent mitochondrial pathway. The expressions of p-P38, P38, P-JNK, JNK, P-ERK and ERK were measured by western blot assay after $24 \mathrm{~h}$ of exposure to furanodienone $(150 \mu \mathrm{M})$ plus NAC $(10 \mathrm{mM})$ in both cells. (c) RKO cells were pretreated with or without $20 \mu \mathrm{M}$ U0126, SP600125 or SB202190 for $1 \mathrm{~h}$ followed by furanodienone $(150 \mu \mathrm{M})$ treatment for an additional $24 \mathrm{~h}$. Expressions of cleaved caspase-8, -9 and -3 were determined by western blotting

Figure 4 Furanodienone increases ROS production that actions upstream of the mitochondrial pathway. (a) Fluorescence images of cells were observed using DCFH-DA probe at a magnification of $\times 100$. Cells were pretreated with or without $10 \mathrm{mM} \mathrm{NAC}$ for $2 \mathrm{~h}$, followed by $150 \mu \mathrm{M}$ furanodienone exposure for $24 \mathrm{~h}$. (b) Changes of MDA level, SOD and CAT activity, and GSH content at $24 \mathrm{~h}$ in furanodienone-treated cells. After exposure to $150 \mu \mathrm{M}$ furanodienone plus pretreatment with or without $10 \mathrm{mM}$ NAC for $2 \mathrm{~h}$, the production of MDA, activity of SOD and CAT, and GSH content were measured. Date are expressed as mean \pm S.D. from three independent experiments. (c) Cells were preincubated with $10 \mathrm{mM}$ of NAC for $2 \mathrm{~h}$ before treatment with $150 \mu \mathrm{M}$ of furanodienone for $24 \mathrm{~h}$, and the cell viability was measured by CCK-8 assay. (d) In the absence or presence of NAC, the cleaved caspase-3, -9 and PARP cleavage proteins exposure of $150 \mu \mathrm{M}$ furanodienone were quantified by western blotting. (e) Total ROS was determined using DCFH-DA probe $(10 \mu \mathrm{M})$. Cells pretreatment with $10 \mathrm{mM}$ NAC or $100 \mu \mathrm{M} z$-VAD-fmk for $2 \mathrm{~h}$ were then treated using $150 \mu \mathrm{M}$ furanodienone for $24 \mathrm{~h}$, and ROS level was measured by flow cytometry. ${ }^{*} P<0.05,{ }^{*} P<0.01$ versus control, ${ }^{\#} P<0.05$ for Fur versus NAC+Fur 
a

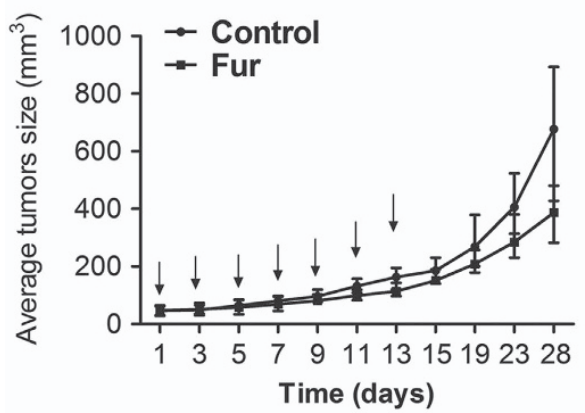

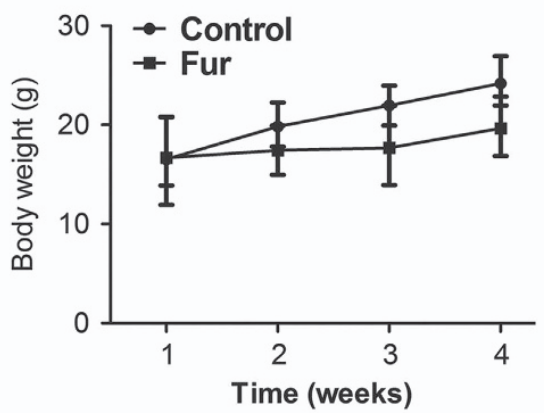

C

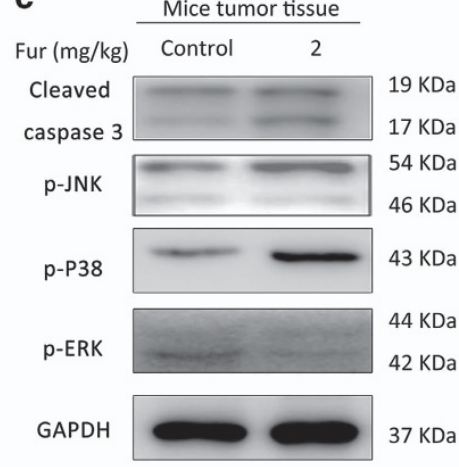

d

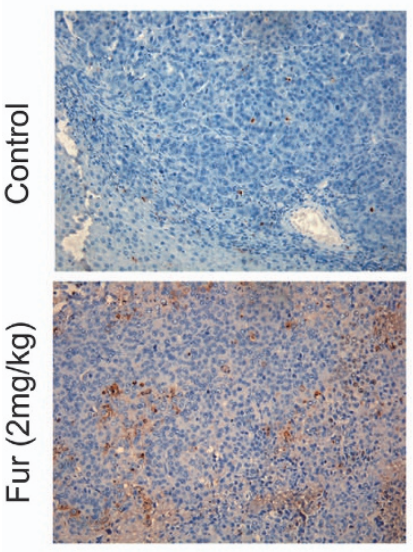

p-JNK
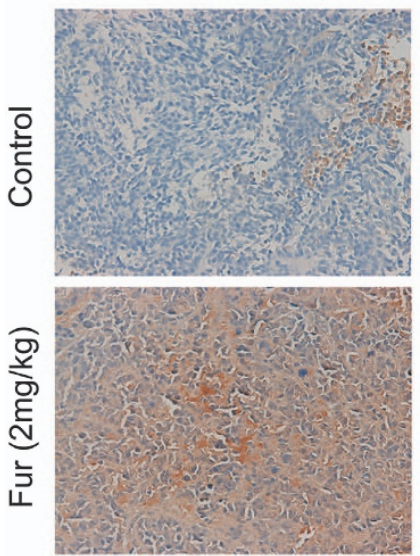

HE
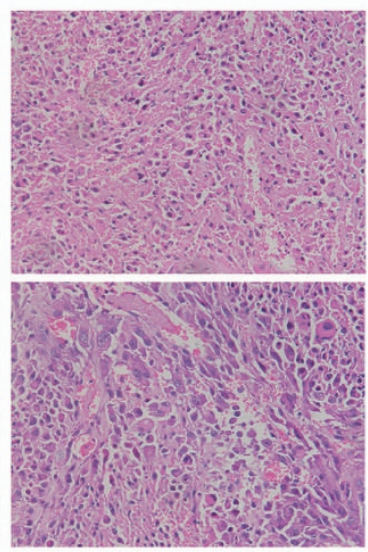

p-P38
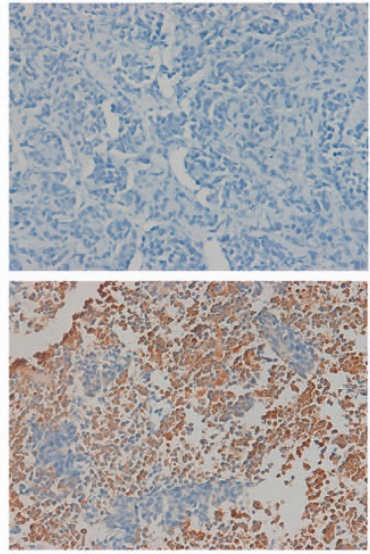

cleaved caspase 3
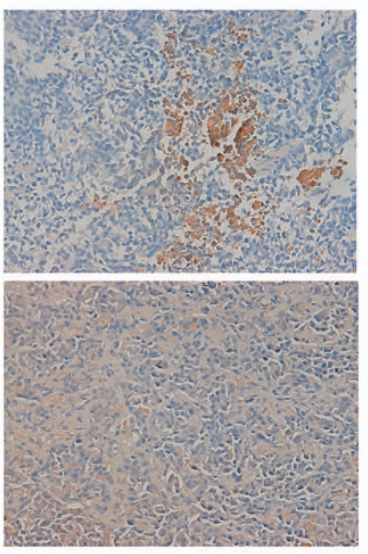

p-ERK
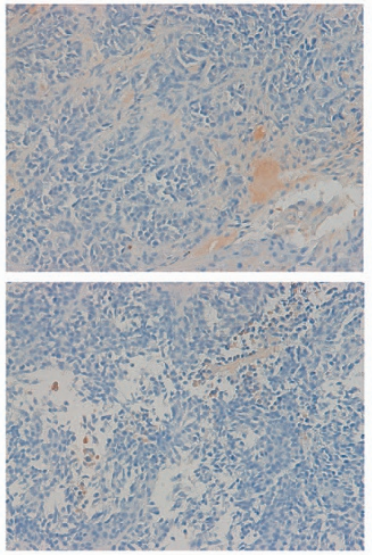
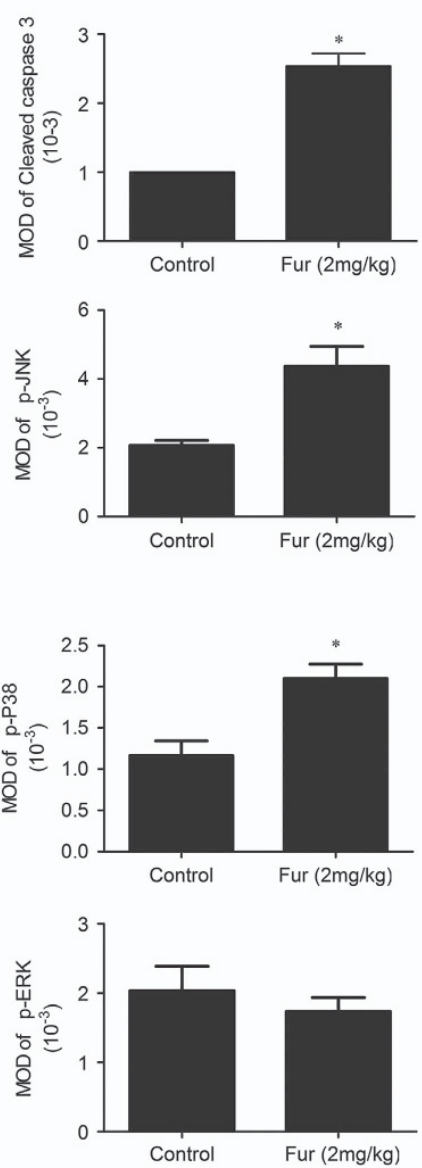

Figure 6 Furanodienone inhibits tumorigenesis of human colorectal xenograft in vivo. RKO cells were inoculated subcutaneously into the right flank of BALB/c-nu. When the average size of tumors reached $50 \mathrm{~mm}^{3}$, mice were randomly divided into two groups receiving intraperitoneal injections with $10 \%$ DMSO or furanodienone (2 mg/kg) every other day during 2 weeks. (a and $\mathbf{b}$ ) Tumor sizes and body weights were measured on a weekly basis. (c) The level of cleaved caspase-3, p-JNK, p-P38 and p-ERK in tumor xenograft tissues was detected by western blot. (d) The apoptotic status in tumor tissues was assessed by TUNEL assay. HE staining was used to evaluated the histology. The expression of cleaved caspase-3, p-JNK, p-P38 and p-ERK was examined by immunohistochemistry, and mean optical density of which were quantified by Image Pro-Plus (IPP, Media Cybernetics, BD Biosciences, Mountain View, CA, USA). ${ }^{*} P<0.05$, significantly different compared with control

Growing evidence in recent years demonstrates the possible interdependent relationship between the MAPKs pathway and oxidative stress in apoptosis. MAPKs are important mediators playing a pivotal role in modulating the actions of related mitochondrial proteins, including ERK1/2, JNK and p38. Generally speaking, the activation of ERK $1 / 2$ promotes cell proliferation, opposing the proapoptotic functions exerted by the stress-activated JNK and p38 MAPK pathways. ${ }^{48,49}$ In the present study, we found there was a significant increase in JNK and p38 phosphorylation, while reduced in ERK1/2 phosphorylation when treated with furanodienone. Pretreatment with NAC reserved the furanodienone-induced JNK and p38 MAPK phosphorylation (Figure 6b). Previous reports have shown that activation of 


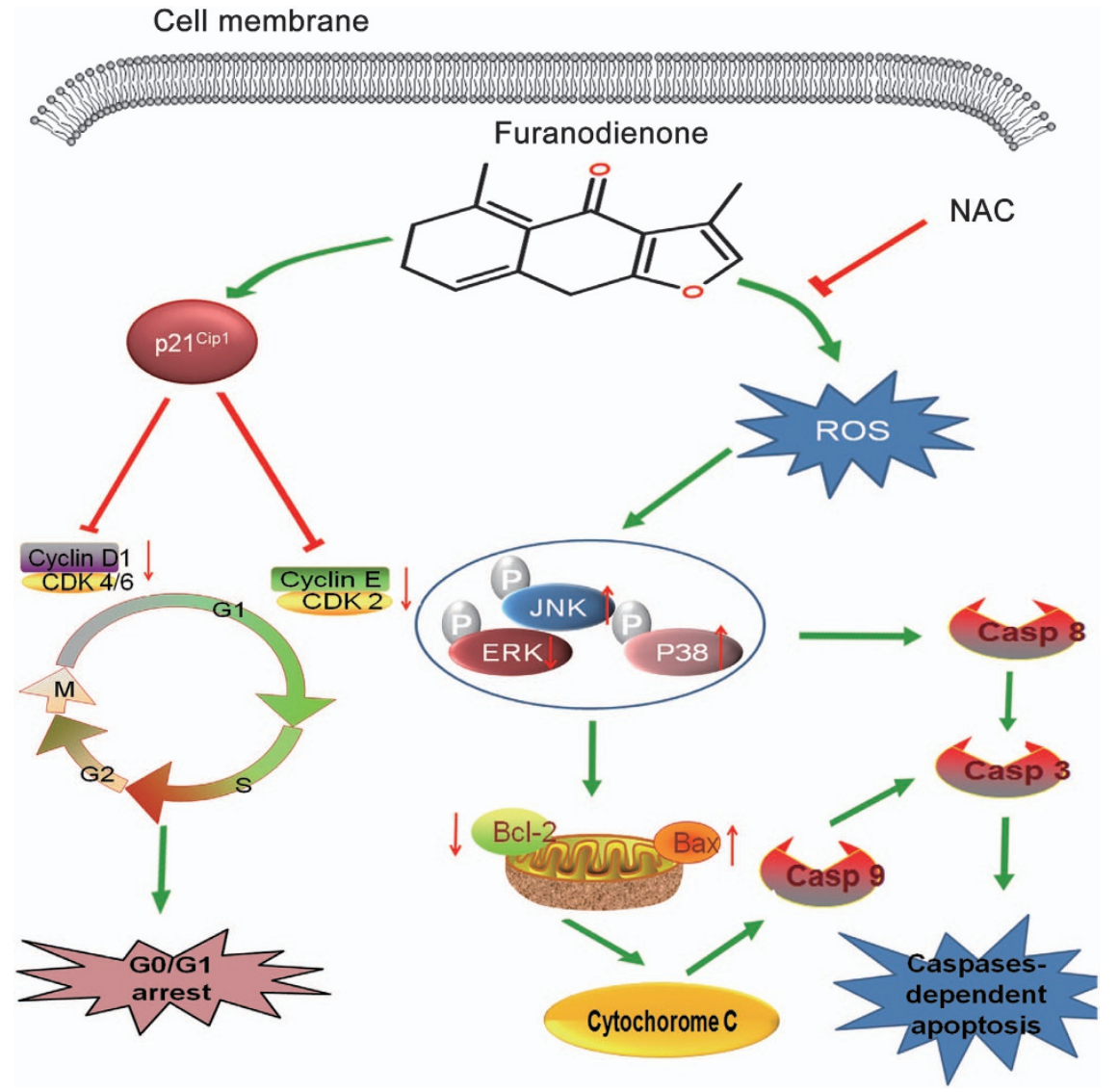

Figure 7 A schematic diagram of G0/G1 phase arrest and ROS-dependent MAPKs pathway in which furanodienone induces cell growth inhibition and cell death in CRC cells

MAPKs signaling pathway modulates the expression of pro or anti-apoptotic proteins (Bax and $\mathrm{Bcl}-2$ ) translocated onto mitochondria dependent of the production of ROS, which initiates the mitochondrial-derived apoptosis. ${ }^{23,50}$ Our study showed that JNK and p38 inhibitors reversed the furanodienone-induced increasing expressions of cleaved caspase-8, -9 and -3 , while ERK1/2 inhibitor showed an opposite trend, indicating MAPKs participated in the mitochondrial apoptotic pathway, but whether the apoptosis regulates the activity of pro or anti-apoptotic proteins should be further studied. Taken together, our results illustrated that furanodienone triggered apoptosis through activation of ROS-dependent MAPKs-mediated caspase-dependent pathway (Figure 7).

In conclusion, our study for the first time identifies furanodienone-induced antitumor effects on CRC cells in vitro and in vivo. We found that furanodienone significantly induced G0/G1 phase arrest and caused cell apoptosis via ROS-dependent MAPKs-mediated mitochondrial pathway. We also demonstrated that furanodienone significantly decreased tumor growth in BALB/c-nu mice bearing xenografts. Overall, furanodienone can be regarded as a leading compound to explore a potential safe drug with low toxicity targeting on CRC. Moreover, this study provided insight into molecular mechanisms on furanodienone-induced cell death, which may aid the development of clinical usage of a novel drug against CRC.

\section{Materials and Methods}

Reagents, chemicals and antibodies. Furanodienone ( $\leqslant 98 \%)$ and 5-FU were purchased from Shanghai Yuanye Bio-Technology Co., Ltd, (Shanghai, China). A stock solution of furanodienone at $4 \mathrm{mM}$ was prepared in dimethyl sulfoxide (DMSO; Sigma, St. Louis, MO, USA) and stored at $-20^{\circ} \mathrm{C}$, while that of $5-\mathrm{FU}$ was prepared in phosphate-buffered saline (PBS) and stored at $4{ }^{\circ} \mathrm{C}$. Dulbecco's modified Eagle's medium (DMEM) and $1 \times$ (PBS, pH 7.4) were obtained from Jinuo Biotechnology (Hangzhou, China). Caspase-3, -8 and -9 Activity Assay Kits, Reactive oxygen species Assay Kit, BCA protein assay Kit and Cell Cycle and Apoptosis Analysis Kits were purchased from Beyotime Biotechnology (Suzhou, China). The NAC was purchased from Sigma Chemical Co. (St. Louis, MO, USA), and inhibitors z-VAD-fmk, z-LEHD-fmk, U0126, SP600125 and SB202190 were afforded by Shanghai Qiangzhi Bio-Technology Co., Ltd, (Shanghai, China). The primary antibodies: p21 ${ }^{\mathrm{Cip} 1}$, CDK 4, cyclin D1, CDK 6, CDK 2, cyclin E, caspase-8, -3 and -9 , cleaved caspase-8, -3 and -9 , cleaved PARP, Bax, Bcl-2, Bcl-xl, cytochrome c, AIF, Smac/DIABLO, survivin, p-p38, p38, p-JNK, JNK, p-ERK, ERK, $\alpha$-tubulin and GAPDH were afforded by Cell Signaling Technology (Beverly, MA, USA).

Cell culture. Human colon adenocarcinoma cells were gifted from the Institute of Clinical Translational Research, Shanghai General Hospital (Shanghai, China). All of these cells were incubated in high-glucose DMEM supplemented with $10 \%$ fetal bovine serum (Gibco Laboratories, Shanghai, China) and 1\% penicillin/ streptomycin $(100 \mu \mathrm{g} / \mathrm{ml}$ for streptomycin, $100 \mathrm{U} / \mathrm{ml}$ for penicillin; Gibco Laboratories) at $37^{\circ} \mathrm{C}$ in a $5 \% \mathrm{CO}_{2}$ humidified atmosphere.

Cell proliferation assessment by CCK-8 assay. Cell proliferation was determined with the CCK-8 assay (Dojindo, Tokyo, Japan). To evaluate the antiproliferative effect of furanodienone on human CRC cells, cell suspensions $\left(8 \times 10^{4} / \mathrm{ml}\right)$ were seeded in 96 -well plates in growth medium, overnight. Cells were treated with various concentrations of furandienone $(50,100,150,200,250,300$, 350 and $400 \mu \mathrm{M}$ ) and the group treated with $0.1 \%$ DMSO was taken as control. At 
appropriate time points (i.e., 24,48 or $72 \mathrm{~h}$ ), $90 \mu$ l fresh medium was incubated with $10 \mu$ l CCK- 8 solution in each well for $2 \mathrm{~h}$ at $37^{\circ} \mathrm{C}$ before absorbance was read at $450 \mathrm{~nm}$ wavelength using a microplate reader (Bio-Tek, San Jose, CA, USA).

Clone formation assay. Cells at a density of 500 cells per well were evenly dispersed on six-well plates followed by furanodienone (75 and $150 \mu \mathrm{M})$ or 5 -FU $(100 \mu \mathrm{M})$ treatment for 10 days. After washing with PBS, the visible colonies were fixed for $30 \mathrm{~min}$ in $4 \%$ paraformaldehyde and stained with crystal violet for $20 \mathrm{~min}$ at room temperature. Then the counts of established cell colonies $>50$ were manually scored and the images were recorded by a digital camera. ${ }^{12}$

Cell cycle analysis. Cells at a density of $1 \times 10^{6}$ cells per well were plated on a six-well plate and then exposed to varying concentrations $(50,100$ and $150 \mu \mathrm{M})$ of furanodienone for $24 \mathrm{~h}$. After treatment, both detached and attached cells were collected and centrifuged at 1000 r.p.m./min for $5 \mathrm{~min}$ at $4{ }^{\circ} \mathrm{C}$. Washed twice with PBS, pelleted cells were fixed in $500 \mu \mathrm{l} 70 \%$ cold ethanol for at least $2 \mathrm{~h}$. Before analysis using flow cytometry, cells were washed again with PBS and incubated with $100 \mu \mathrm{l}$ RNase. The resulting suspension was placed at $37^{\circ} \mathrm{C}$ for $30 \mathrm{~min}$. Subsequently, a volume of $400 \mu \mathrm{l}$ propidium iodide was added into the suspension, and cells were stained at $4{ }^{\circ} \mathrm{C}$ in the dark for $30 \mathrm{~min}$. Cell cycles were detected at $488 \mathrm{~nm}$ using BD Accuri $\mathrm{C} 6$ and analysis were conducted with BD CFlow software (BD Biosciences, Mountain View, CA, USA).

RNA isolation and real time RT-qPCR. The cell cycle regulatory gene expressions of P21 Cip1, CDK 4, cyclin D1 and CDK 6 mRNA in RKO cells were measured by RT-qPCR analysis. Total RNA was extracted using Trizol reagent (Takara, Tokyo, Japan) according to the manufacturer's instructions. RNA from each sample $(1 \mu \mathrm{g})$ was used to synthesize complementary DNA using RevertAid First Strand cDNA Synthesis Kit (Fermentas, Billerica, MA, USA) according to recommendations. RT-PCR was cycled between $95^{\circ} \mathrm{C}$ for $15 \mathrm{~s}$ and $60^{\circ} \mathrm{C}$ for $1 \mathrm{~min}$ for 40 cycles, after a $95^{\circ} \mathrm{C}$ denaturation step for 5 min. Endogenous control was that of GAPDH to normalize the detected mRNA expressions. The primer pairs of P21 ${ }^{\text {Cip } 1}$, CDK 4, cyclin D1, CDK 6 and GAPDH were as follows: P21 ${ }^{\text {Cip1 }}$ (F) $5^{\prime}$ GACTGTGATGCGCTAATGGC-3', (R) 5'-CCGTGGGAAGGTAGAGCTTG-3'; CDK 4 (F) 5'-CAGCTTGCCCGAGTTCTACT-3', (R) 5'-TGTCCTCAGAGTTAGCCGGA -3'; cyclin D1 (F) 5'-CAGATCATCCGCAAACACGC-3', (R) 5'-AAGTTGTTGGG GCTCCTCAG-3'; CDK 6 (F) 5'-AGGAAGGCAAACGTGACC-3', (R) 5'-TATTGT CCCAAGGCTGGCTC-3'; GAPDH (F) 5'-GATGCCCCCATGTTCGTCAT-3', (R) 5' TCTTCTGGGTGGCAGTGATG-3'.

DAPI staining. Cells were fixed with $4 \%$ paraformaldehyde for $30 \mathrm{~min}$ at room temperature. Washing with PBS, $100 \mu \mathrm{l}$ DAPI (Beyotime Biotechnology) was added to the fixed cells for $5 \mathrm{~min}$ and the cells were assessed by fluorescence microscopy (Leica, Wetzlar, Germany).

Cell apoptosis by flow cytometry. The measurement of cell apoptosis was undertaken using an Annexin V-FITC/PI Apoptosis detection kit (BD Pharmingen, San Jose, CA, USA). Briefly, cells were plated on a six-well plate and then maintained at $37^{\circ} \mathrm{C}$ in a humidified atmosphere with $5 \% \mathrm{CO}_{2}$. After adherent culture, furanodienone in $0.1 \%$ DMSO or 5 -FU was added into each well, for $24 \mathrm{~h}$. Both floating and adherent cells were collected, washed twice with cold PBS and resuspended in $1 \times$ binding buffer. The cells were incubated with $5 \mu \mathrm{l}$ Annexin V-FITC and $5 \mu \mathrm{IPI}$ for $15 \mathrm{~min}$ at room temperature in the dark. A $400 \mu$ $1 \mathrm{x}$ binding buffer was added into each sample before being analyzed using flow cytometry (BD Accuri C6) with cell counts of $1 \times 10^{4}$ for each measurement.

Ethidium bromide and acridine orange staining for apoptosis detection. Confluent cell monolayers were exposed to furanodienone or 5-FU for $24 \mathrm{~h}$ at $37^{\circ} \mathrm{C}$. Washed with PBS for twice, cells were immediately treated with a dye mixture containing EB $(100 \mu \mathrm{g} / \mathrm{ml})$ and $\mathrm{AO}(100 \mu \mathrm{g} / \mathrm{ml})$ in a $1: 1$ ratio for $5 \mathrm{~min}$. Subsequently, cells were imaged using a florescence microscope equipped with a digital imaging system (Leica).

Lactate dehydrogenase release assay. The cycotoxicity of furanodienone on human colon cells was assessed with LDH cytotoxicity Assay Kit (Jiancheng, Nanjing, China) according to the manufacture's instructions.

Assays for activation of caspase-3, -8, -9. Briefly, floating and attached cells were collected after washing twice with ice-cold PBS and they were resuspended in lysis buffer on ice for $30 \mathrm{~min}$. Next, the lysate was centrifuged at $18000 \times \mathrm{g}$ at $4{ }^{\circ} \mathrm{C}$ for $10 \mathrm{~min}$ and the supernatant was transferred to a $1.5 \mathrm{ml}$ centrifuge tube. The total protein concentration of each sample in the supernatant was measured using the Bradford protein assay kit (Beyotime Institute of Biotechnology, Jiangsu, china). Subsequently, a mixture of $40 \mu \mathrm{l}$ detection buffer, $50 \mu \mathrm{l}$ cellular extracts and $10 \mu \mathrm{l}$ peptide substrates, respectively, Ac-DEVD-pNA, Ac-IETD-pNA and Ac-LEHD-pNA were co-incubated for $2 \mathrm{~h}$ at $37^{\circ} \mathrm{C}$ in a 96-well plate. The release of $p N A$ was measured at $405 \mathrm{~nm}$ with a spectrophotometer and the relative activity of caspase was calculated as the folds of treated cells to the control.

Mitochondrial membrane potential assay. The loss of mitochondrial membrane potential, which is one of the early key events linked to apoptosis, was determined using the mitochondria-specific cationic fluorescence dye JC-1 (Beyotime Biotechnology). Treatment was carried out for $24 \mathrm{~h}$, Cells were then suspended in $1 \times \mathrm{JC}-1$ staining buffer for $30 \mathrm{~min}$, co-incubating at $37^{\circ} \mathrm{C}$ in the dark. The level of MMP was monitored by flow cyotometry for quantitative assessment. The red and green fluorescence were detected by FL-2 and FL-1 channels, respectively, using flow cytometer (BD Accuri $\mathrm{C} 6$ ), and the change in MMP was calculated as the folds of the green fluorescence intensity to that of the control.

ATP determination. The intracellular ATP content exposure to furanodienone in RKO and HT-29 cells was determined quantitatively using the ATP assay kit (Beyotime Biotechnology) according to the manufacturer's instructions.

Measurement of intracellular ROS. The level of intracellular ROS was estimated quantitatively using an peroxide-sensitive fluorescent probe DCFH-DA ( $2^{\prime}, 7$-dichlorofluorescein diacetate), which is oxidized in the presence of peroxides to the highly fluorescent DCF $\left(2^{\prime}, 7\right.$-dichlorofluorescein).$^{51}$ Cells plated in six-well plates $\left(1 \times 10^{6}\right.$ cells per well) were exposed to furanodienone $(150 \mu \mathrm{M})$ for $24 \mathrm{~h}$ in the absence or presence of $10 \mathrm{mM}$ NAC or $100 \mu \mathrm{M} z-V A D$-fmk for $2 \mathrm{~h}$ at $37^{\circ} \mathrm{C}$ in incubator. The cells were then co-incubated with $10 \mu \mathrm{M}$ DCFH-DA at $37^{\circ} \mathrm{C}$ for $30 \mathrm{~min}$ before the fluorescent intensity of DCF was analyzed by flow cytometry (BD C6 Biosciences, San Jose, CA, USA) with an excitation wavelength of $488 \mathrm{~nm}$ and emission wavelength of $525 \mathrm{~nm}$. The images of the stained cells were taken by inverted fluorescence microscopy immediately (Leica).

Assessment of oxidative damage. After exposure to furanodienone with or without the pretreatment of $10 \mathrm{mM} \mathrm{NAC}$ for $24 \mathrm{~h}$, cells were washed three times with cold PBS and then lysed in $500 \mu \mathrm{l}$ lysis buffer for $30 \mathrm{~min}$ on ice. Centrifuged at $150000 \times g$ for $3 \mathrm{~min}$ at $4{ }^{\circ} \mathrm{C}$, the total concentration of proteins was determined using BCA protein assay kit (Beyotime Biotechnology). The lipid peroxidation product MDA and GSH level were measured by a micromount MDA Kit and glutathione Kit, both of which were provided from Nanjing Jiancheng Bioengineering Institute (Nanjing, China). The activities of SOD and CAT were analyzed using Total Superoxide Dismutase Assay Kit and Catalase Assay Kit (Nanjing Jiancheng Bioengineering Institute), respectively.

Western blot analysis. The expression level of targeted protein was investigated by western blotting. Cell pellet was lysed in $100 \mu$ l modified RIPA buffer for $30 \mathrm{~min}$ on the ice, and the concentration of total proteins was determined by a BCA protein assay kit (Beyotime Biotechnology). Proteins $(30 \mu \mathrm{g})$ for each sample were separated on $10-12 \%$ SDS-PAGE at $100 \mathrm{~V}$ for $1.5 \mathrm{~h}$ and transferred onto polyvinyldene difluoride membranes at $300 \mathrm{~mA}$ for $2 \mathrm{~h}$ afterward. The membranes were blocked with $5 \%(\mathrm{w} / \mathrm{v})$ non-fat milk in Tris-buffered saline-Tween (TBST) buffer for $1.5 \mathrm{~h}$ at room temperature and then incubated with primary antibody at $4{ }^{\circ} \mathrm{C}$ overnight. Washed three times with TBST buffer, the blots were then incubated with HRP-conjugated secondary antibody for $1 \mathrm{~h}$ at room temperature. Each band was developed using enhanced chemiluminescence kit (Millipore, Billerica, MA, USA).

Human CRC xenograft experiment. Twelve male BALB/C-nu mice (Shanghai Slac Laboratory Animal Co., Ltd, Shanghai, China) at 4 weeks of age were maintained in a standard animal laboratory supplied with sterilized water and food. RKO cells at a density of $5 \times 10^{6} / \mathrm{ml}$ were suspended in cold PBS, and a volume of $150 \mu \mathrm{l}$ cell suspension was administrated subcutaneously in the right flank of each mouse. When the tumor size reached $50 \mathrm{~mm}^{3}$, the mice were randomly divided into two groups; control (10\% DMSO) and furanodienone (2 mg) diluted with $10 \%$ DMSO. Both groups received intraperitoneal injection every other 
day for seven times. The tumor size was monitored every 2 days for a period of 4 weeks with a sliding caliper and calculated using the formula: length $\times$ width $^{2} / 2$. At the end point of the experiment, the mice were killed and the tumor tissues were removed from the mice, and fixed in 5\% formalin for the next immunohistochemistry, HE and TUNEL assays. All the animal-related procedures were approved by the Animal Care and Use Committee of Shanghai General Hospital, Shanghai, China.

TUNEL assay. Apoptosis detection in the tumor tissues was identified using the terminal deoxynucleotidyl transferase-mediated dUTP nick end labeling (TUNEL) assay with In Situ Cell Death Detection Kit, Fluorescein (Roche Diagnostics, Mannheim, Germany). Formalin-fixed tumor tissues were embedded in paraffin and cut into serial sections $(4 \mu \mathrm{m})$. In brief, after being deparaffinized with xylene and ethanol, and hydrated proteinase $\mathrm{K}(20 \mu \mathrm{g} / \mathrm{ml})$ for $25 \mathrm{~min}$ at $37^{\circ} \mathrm{C}$, slides were washed with PBS for several times and then incubated with TUNEL reaction mixture prepared freshly for $1 \mathrm{~h}$ at $37^{\circ} \mathrm{C}$ in a moist chamber. After being again washed, the apoptotic cells on the slides were observed under fluorescence microscopy (Leica).

Histopathology and immunohistochemistry. Following a hydration process, the slides were exposed to hematoxylin for 15 min and immersed in 1\% hydrochloric acid in $75 \%$ ethanol for $30 \mathrm{~s}$. The slides were stained with eosin for $5 \mathrm{~min}$ followed by dehydration. Finally, the slides were immersed in xylene and mounted. For immunohistochemical staining, the slides were deparaffinized in xylene and rehydrated with graded alcohol and incubated in $3 \% \mathrm{H}_{2} \mathrm{O}_{2}$ to block the endogenous peroxidase activity. Antigen retrieval was performed in $10 \mathrm{mM}$ sodium citrate buffer ( $\mathrm{pH} \mathrm{6.0)}$ for $30 \mathrm{~min}$ by boiling the slides. Then, slides were blocked in $10 \%$ normal goat serum for $15 \mathrm{~min}$, followed by incubation with cleaved caspase-3, p-JNK, p-P38 and p-ERK at $4{ }^{\circ} \mathrm{C}$ overnight in a moist chamber. Afterward, slides were washed in PBS for three times and then incubated with the second antibody for $30 \mathrm{~min}$ at room temperature. Immunoreactivity was visualized using the Vectastain Elite DAB KIT (Vector Laboratories, Burlingame, CA, USA). Image Pro-Plus 6.0 (IPP, Media Cybernetics, BD Biosciences) was used for digital analysis.

Statistical analysis. All data were repeated at least three times independently for statistical calculations and were expressed as mean \pm S.D. Statistical significance $\left({ }^{*} P<0.05\right.$, ${ }^{* *} P<0.01$ and ${ }^{* *} P<0.0001$, compared to the control group) was determined by GraphPad Prism 5 (GraphPad Software, Inc., La Jolla, CA, USA) using one-way ANOVA analysis or Student's t-test.

\section{Conflict of Interest}

The authors declare no conflict of interest.

Acknowledgements. We gratefully acknowledge the financial support of the Shanghai Committee of Science and Technology (16401901400), the Health Bureau of Shanghai, China (2011ZJ021) and the State Key Laboratory of Clinical Pharmacology Department of Shanghai General Hospital, Shanghai, China.

1. Wu W, Guo F, Ye J, Li Y, Shi D, Fang D et al. Pre- and post-diagnosis physical activity is associated with survival benefits of colorectal cancer patients: a systematic review and meta-analysis. Oncotarget 2016; 7: 52095-52103.

2. Siegel RL, Miller KD, Jemal A. Cancer statistics, 2016. CA Cancer J Clin 2016; 66: 7-30.

3. Chen W, Zheng R, Zhang S, Zhao P, Zeng H, Zou X et al. Annual report on status of cancer in China, 2010. Chin J Cancer Res 2014; 26: 48-58.

4. Wu J, Long Z, Cai H, Du C, Liu X, Yu S et al. High expression of WISP1 in colon cancer is associated with apoptosis, invasion and poor prognosis. Oncotarget 2016; 7: 49834-49847.

5. Zhang $Q, M a X, X u Q$, Qin J, Wang Y, Liu $Q$ et al. Nomograms incorporated serum direct bilirubin level for predicting prognosis in stages II and III colorectal cancer after radical resection. Oncotarget 2016; e-pub ahead of print 19 Aug 2016; do:10.18632/ oncotarget.11424.

6. DeSantis CE, Lin CC, Mariotto AB, Siegel RL, Stein KD, Kramer JL et al. Cancer treatment and survivorship statistics, 2014. CA Cancer J Clin 2014; 64: 252-271.

7. Zorofchian Moghadamtousi S, Karimian H, Khanabdali R, Razavi M, Firoozinia M, Zandi K et al. Anticancer and antitumor potential of fucoidan and fucoxanthin, two main metabolites isolated from brown algae. ScientificWorldJournal 2014; 2014: 768323.

8. Deng C, Li N, Zhang X. Rapid determination of essential oil in Acorus tatarinowii Schott. by pressurized hot water extraction followed by solid-phase microextraction and gas chromatography-mass spectrometry. J Chromatogr A 2004; 1059: 149-155.

9. Rouhollahi E, Zorofchian Moghadamtousi S, Paydar M, Fadaeinasab M, Zahedifard M, Hairezaie M et al. Inhibitory effect of Curcuma purpurascens BI. rhizome on HT-29 colon cancer cells through mitochondrial-dependent apoptosis pathway. BMC Complement Altern Med 2015; 15: 15.

10. Sankpal UT, Nagaraju GP, Gottipolu SR, Hurtado M, Jordan CG, Simecka JW et al. Combination of tolfenamic acid and curcumin induces colon cancer cell growth inhibition through modulating specific transcription factors and reactive oxygen species. Oncotarget 2016; 7: 3186-3200.

11. Huang GM, Sun Y, Ge X, Wan X, Li CB. Gambogic acid induces apoptosis and inhibits colorectal tumor growth via mitochondrial pathways. World J Gastroenterol 2015; 21 6194-6205.

12. Zhao D, Lin F, Wu X, Zhao $Q$, Zhao B, Lin $P$ et al. Pseudolaric acid $B$ induces apoptosis via proteasome-mediated Bcl-2 degradation in hormone-refractory prostate cancer DU145 cells. Toxicol In Vitro 2012; 26: 595-602.

13. Gao D, Wang $Y, X i e W$, Yang $T$, Jiang $Y$, Guo $Y$ et al. Metabolomics study on the antitumor effect of marine natural compound flexibilide in HCT-116 colon cancer cell line. J Chromatogr B Analyt Technol Biomed Life Sci 2016; 1014: 17-23.

14. Makabe H, Maru N, Kuwabara A, Kamo T, Hirota M. Anti-inflammatory sesquiterpenes from Curcuma zedoaria. Nat Prod Res 2006; 20: 680-685.

15. Wang $X$, Jiang $Y, H u D$. Optimization and in vitro antiproliferation of Curcuma wenyujin's active extracts by ultrasonication and response surface methodology. Chem Cent J 2016; 10: 32.

16. Li YW, Zhu GY, Shen XL, Chu JH, Yu ZL, Fong WF. Furanodienone induces cell cycle arrest and apoptosis by suppressing EGFR/HER2 signaling in HER2-overexpressing human breast cancer cells. Cancer Chemother Pharmacol 2011; 68: 1315-1323.

17. Li YW, Zhu GY, Shen XL, Chu JH, Yu ZL, Fong WF. Furanodienone inhibits cell proliferation and survival by suppressing ERalpha signaling in human breast cancer MCF-7 cells. J Cell Biochem 2011; 112: 217-224.

18. Li H, Horke $\mathrm{S}$, Forstermann U. Vascular oxidative stress, nitric oxide and atherosclerosis. Atherosclerosis 2014; 237: 208-219.

19. Yan LJ. Positive oxidative stress in aging and aging-related disease tolerance. Redox Biol 2014; 2: 165-169.

20. Trachootham D, Lu W, Ogasawara MA, Nilsa RD, Huang P. Redox regulation of cell survival. Antioxid Redox Signal 2008; 10: 1343-1374.

21. Shen HM, Liu ZG. JNK signaling pathway is a key modulator in cell death mediated by reactive oxygen and nitrogen species. Free Radic Biol Med 2006; 40: 928-939.

22. Huang HL, Hsieh MJ, Chien MH, Chen HY, Yang SF, Hsiao PC. Glabridin mediate caspases activation and induces apoptosis through JNK1/2 and p38 MAPK pathway in human promyelocytic leukemia cells. PLOS ONE 2014; 9: e98943.

23. Guo C, Yang M, Jing L, Wang J, Yu Y, Li Y et al. Amorphous silica nanoparticles trigger vascular endothelial cell injury through apoptosis and autophagy via reactive oxygen species-mediated MAPK/Bcl-2 and PI3K/Akt/mTOR signaling. Int J Nanomedicine 2016; 11: 5257-5276.

24. Basu A, DuBois G, Haldar S. Posttranslational modifications of Bcl2 family members-a potential therapeutic target for human malignancy. Front Biosci 2006; 11: 1508-1521.

25. Breitschopf K, Haendeler J, Malchow P, Zeiher AM, Dimmeler S. Posttranslational modification of $\mathrm{Bcl}-2$ facilitates its proteasome-dependent degradation: molecular characterization of the involved signaling pathway. Mol Cell Biol 2000; 20: 1886-1896.

26. Ma E, Wang X, Li Y, Sun X, Tai W, Li T et al. Induction of apoptosis by furanodiene in HL60 leukemia cells through activation of TNFR1 signaling pathway. Cancer Lett 2008; 271: 158-166.

27. Li HY, Zhang J, Sun LL, Li BH, Gao HL, Xie T et al. Celastrol induces apoptosis and autophagy via the ROS/JNK signaling pathway in human osteosarcoma cells: an in vitro and in vivo study. Cell Death Dis 2015; 6: e1604.

28. Li CL, Chang L, Guo L, Zhao D, Liu HB, Wang QS et al. Beta-elemene induces caspasedependent apoptosis in human glioma cells in vitro through the upregulation of Bax and Fas/ FasL and downregulation of Bcl-2. Asian Pac J Cancer Prev 2014; 15: 10407-10412.

29. Xu WS, Li T, Wu GS, Dang YY, Hao WH, Chen XP et al. Effects of furanodiene on 95-D lung cancer cells: apoptosis, autophagy and G1 phase cell cycle arrest. Am J Chin Med 2014; 42: 243-255.

30. Wang $\mathrm{X}$, Jiang $\mathrm{Y}, \mathrm{Hu} \mathrm{D}$. Anti-proliferative activity of Curcuma phaeocaulis Valeton extract using ultrasonic assistance and response surface methodology. Prep Biochem Biotechno 2016; 47: 19-31.

31. Novak B, Tyson JJ. Modelling the controls of the eukaryotic cell cycle. Biochem Soc Trans 2003; 31: 1526-1529.

32. Vermeulen K, Van Bockstaele DR, Berneman ZN. The cell cycle: a review of regulation, deregulation and therapeutic targets in cancer. Cell Prolif 2003; 36: 131-149.

33. Saleh AM, Aljada A, El-Abadelah MM, Taha MO, Sabri SS, Zahra JA et al. The anticancer activity of the substituted pyridone-annelated isoindigo $\left(5^{\prime}-\mathrm{Cl}\right)$ involves $\mathrm{GO} / \mathrm{G} 1$ cell cycle arrest and inactivation of CDKs in the promyelocytic leukemia cell line $\mathrm{HL}-60$. Cell Physio Biochem 2015; 35: 1943-1957.

34. Keer JF, Wyllie AH, Currie AR. Apoptosis: a basic biological phenomenon with wide-ranging implications in tissue kinetics. Br J Cancer 1972; 26: 239-257.

35. Kiraz Y, Adan A, Kartal Yandim M, Baran Y. Major apoptotic mechanisms and genes involved in apoptosis. Tumour Biol 2016; 37: 8471-8486.

36. Zimmermann KC, Bonzon C, Green DR. The machinery of programmed cell death Pharmacol Ther 2001; 92: 57-70.

37. Degterev A, Boyce M, Yuan J. A decade of caspases. Oncogene 2003; 22: 8543-8567. 
38. Tamm I, Schriever F, Dorken B. Apoptosis: implications of basic research for clinical oncology. Lancet Oncol 2001; 2: 33-42.

39. Burwell LS, Brookes PS. Mitochondria as a target for the cardioprotective effects of nitric oxide in ischemia-reperfusion injury. Antioxid Redox Signal 2008; 10: 579-599.

40. Cheng G, Guo W, Han L, Chen E, Kong L, Wang L et al. Cerium oxide nanoparticles induce cytotoxicity in human hepatoma SMMC-7721 cells via oxidative stress and the activation of MAPK signaling pathways. Toxicol In Vitro 2013; 27: 1082-1088.

41. Shukla S, Rizvi F, Raisuddin S, Kakkar P. FoxO proteins' nuclear retention and BH3-only protein Bim induction evoke mitochondrial dysfunction-mediated apoptosis in berberine-treated HepG2 cells. Free Radic Biol Med 2014; 76: 185-199.

42. Li YJ, Kawada T, Azuma A. Nrf2 is a protective factor against oxidative stresses induced by diesel exhaust particle in allergic asthma. Oxid Med Cell Longev 2013; 2013: 323607.

43. Li Z, Dong X, Liu H, Chen X, Shi H, Fan Y et al. Astaxanthin protects ARPE-19 cells from oxidative stress via upregulation of Nrf2-regulated phase II enzymes through activation of PI3K/Akt. Mol Vis 2013; 19: 1656-1666.

44. Guo C, Xia Y, Niu P, Jiang L, Duan J, Yu Y et al. Silica nanoparticles induce oxidative stress, inflammation, and endothelial dysfunction in vitro via activation of the MAPK/Nrf2 pathway and nuclear factor-kappaB signaling. Int J Nanomedicine 2015; 10: 1463-1477.

45. Cen J, Zhang L, Liu F, Zhang F, Ji BS. Long-term alteration of reactive oxygen species led to multidrug resistance in MCF-7 cells. Oxid Med Cell Longev 2016; 2016: 7053451.

46. Kim EH, Jang H, Roh JL. A novel polyphenol conjugate sensitizes cisplatin-resistant head and neck cancer cells to cisplatin via Nrf2 inhibition. Mol Cancer Ther 2016; 15: 2620-2629.

47. Maillet A, Yadav S, Loo YL, Sachaphibulkij K, Pervaiz S. A novel Osmium-based compound targets the mitochondria and triggers ROS-dependent apoptosis in colon carcinoma. Cell Death Dis 2013; 4: e653.

48. Junttila MR, Li SP, Westermarck J. Phosphatase-mediated crosstalk between MAPK signaling pathways in the regulation of cell survival. FASEB J 2008; 22: 954-965.
49. Schroeter H, Boyd CS, Ahmed R, Spencer JP, Duncan RF, Rice-Evans C et al. C-Jun $\mathrm{N}$-terminal kinase (JNK)-mediated modulation of brain mitochondria function: new target proteins for JNK signalling in mitochondrion-dependent apoptosis. Biochem J 2003; 372: 359-369.

50. Hsiao PC, Chou YE, Tan P, Lee WJ, Yang SF, Chow JM et al. Pterostilbene simultaneously induced G0/G1-phase arrest and MAPK-mediated mitochondrial-derived apoptosis in human acute myeloid leukemia cell lines. PLOS ONE 2014; 9: e105342.

51. Marvibaigi M, Amini N, Supriyanto E, Abdul Majid FA, Kumar Jaganathan S, Jamil S et al. Antioxidant activity and ROS-dependent apoptotic effect of Scurrula ferruginea (Jack) danser methanol extract in human breast cancer cell MDA-MB-231. PLOS ONE 2016; 11: e0158942.

(c) (i) Cell Death and Disease is an open-access journal published by Nature Publishing Group. This work is licensed under a Creative Commons Attribution 4.0 International License. The images or other third party material in this article are included in the article's Creative Commons license, unless indicated otherwise in the credit line; if the material is not included under the Creative Commons license, users will need to obtain permission from the license holder to reproduce the material. To view a copy of this license, visit http://creativecommons.org/licenses/by/4.0/

(C) The Author(s) 2017

Supplementary Information accompanies this paper on Cell Death and Disease website (http://www.nature.com/cddis) 